\title{
Levitation-jet synthesis of In-O nanoparticles with room-temperature ferromagnetic properties
}

\author{
Iu. G. Morozov ${ }^{\mathrm{a}, *}$, O.V. Belousova ${ }^{\mathrm{a}}$, S. Firth ${ }^{\mathrm{b}}$, I.P. Parkin ${ }^{\mathrm{b}}$, M.V. Kuznetcov ${ }^{\mathrm{c}}$ \\ a Institute of Structural Macrokinetics and Materials Science, Russian Academy of Sciences, 8 Academician Osipyan Street, Chernogolovka, Moscow Region 142432, Russia \\ ${ }^{\mathrm{b}}$ Department of Chemistry, University College London, 20 Gordon Street, London WC1H OAJ, UK

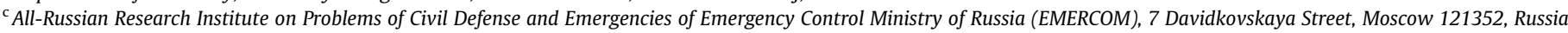

A R T I C L E I N F O

Article history:

Received 10 October 2016

Received in revised form 31 March 2017

Accepted 19 May 2017

Available online 31 May 2017

Keywords:

Nanoparticles (NPs)

Room-temperature ferromagnetism (RTFM)

Levitation-jet generator

Indium oxide

Optical properties

\begin{abstract}
A B S T R A C T
Octahedral and roughly spherical $\operatorname{In}-\mathrm{In}_{2} \mathrm{O}_{3}$ nanoparticles ranging in average particle size from 30 up to $300 \mathrm{~nm}$ were prepared by levitation-jet aerosol synthesis through condensation of metal indium vapor in helium gas flow with gaseous oxygen/air injection at ambient and reduced pressure. Scanning electron microscopy (SEM), X-ray diffraction (XRD), BET measurements, UV-vis, FT-IR, Raman, XPS, and vibratingsample magnetometry (VSM) characterized the nanoparticles. Room-temperature ferromagnetism with maximum magnetization of up to $0.17 \mathrm{emu} / \mathrm{g}$ was recorded for the nanoparticles. The results indicate a predominant role of the actual microstructure on the nanoparticle properties. It is suggested that the observed ferromagnetic ordering may be related to intrinsic defects at the $\mathrm{In} / \mathrm{In}_{2} \mathrm{O}_{3}$ interface structure of such a composite material. This suggestion is in good agreement with the results of optical and XPS experiments on the NPs.
\end{abstract}

(c) 2017 The Society of Powder Technology Japan. Published by Elsevier B.V. and The Society of Powder Technology Japan. All rights reserved.

\section{Introduction}

In 2004, an unexpected room-temperature ferromagnetism (RTFM) was found in undoped $\mathrm{HfO}_{2}$ thin films by Venkatesan et al. [1]. The existence of RTFM, also termed " $d^{0}$ ferromagnetism" [2] in metal oxides, makes these materials a potential candidate for future spin coupled optoelectronic devices [3,4]. Up to now, RTFM has been observed in a number of pure low dimensional nanosized metal oxides, such as $\mathrm{SnO}_{2}[4,5], \mathrm{ZnO}[6,7], \mathrm{CuO}[8,9]$, $\mathrm{MgO}[10,11], \mathrm{Al}_{2} \mathrm{O}_{3}[5,12], \mathrm{CaO}$ [13], etc. It has been identified that $d^{0}$ ferromagnetism is closely related to the existence of defects at the surface regions [14]. These defects may confine the compensating charges in molecular orbitals, forming local magnetic moments, and RTFM may be established only if the defect concentration essentially exceeds that of its equilibrium magnitude [15]. Due to their large surface-to-volume ratios, $d^{0}$ ferromagnetism has been observed in various oxide nanostructures. It is now believed that both - the surface non-stoichiometry and the defects of oxide nanostructures play a crucial role in the observance of RTFM, since conventional ideas of magnetism are unable to account for $d^{0}$ ferromagnetism [16]. However, the main obstacle to the use such

\footnotetext{
* Corresponding author.

E-mail addresses: morozov@ism.ac.ru (I.G. Morozov), s.firth@ucl.ac.uk (S. Firth), i.p.parkin@ucl.ac.uk (I.P. Parkin), maxim1968@mail.ru (M.V. Kuznetcov).
}

materials for the fabrication of potential devices is the lack of understanding of the role of defects [14]. This somewhat controversial research topic definitely requires further detailed investigations. Such studies are not only crucial for technological applications, but also to further understand important fundamental aspects of the defect-induced properties of undoped metal oxides.

Indium oxide $\left(\mathrm{In}_{2} \mathrm{O}_{3}\right)$ is a transparent wide band gap $(3.75 \mathrm{eV})$ oxide, which has a wide range of technological applications, including flat-panel displays and gas sensors, due to remarkable combination of optical transparency and electrical conductivity combined with a high work function [17]. The functional properties in this oxide are, to a large extent, controlled by the presence of native point defects [18]. Moreover, if any ferromagnetism is found in the indium oxide nanoparticles, then it must be mediated by defects because bulk $\mathrm{In}_{2} \mathrm{O}_{3}$ is a typical diamagnetic inorganic material [19].

It should be noted, that magnetic properties of $\operatorname{In}_{2} \mathrm{O}_{3}$ nanoparticles (NPs) compared with thin films [16,20-22] is still a developing subject. Prakash at al. discovered that undoped $\mathrm{In}_{2} \mathrm{O}_{3}$ NPs show weak RT ferromagnetism with saturated magnetization of $\sim 2$ memu/g [18]. Naeem, Qaseem et al. founded that only smaller size nanoparticles ( 5 and $12 \mathrm{~nm}$ ) exhibit intrinsic or defect-mediated $d^{0}$ ferromagnetism (of $5 \mathrm{memu} / \mathrm{cm}^{3}$ ), which may be attributed to the uncompensated surface spins [23,24]. Patel et al. firstly prepared monodisperse NPs with an average diameter of $11 \mathrm{~nm}$ by using a solvothermal method [19]. They supposed the origin of RTFM (of 
$6 \mathrm{memu} / \mathrm{g}$ ) might be due to exchange interactions among localized electron spin moments resulting from the oxygen vacancies. On the other hand, Chandradass et al. established diamagnetic behavior in $12 \mathrm{~nm} \mathrm{In} \mathrm{O}_{3} \mathrm{NPs}$ [25], and Krishna et al. discovered that pure $\mathrm{In}_{2} \mathrm{O}_{3}$ powders with crystallite sizes of $40-50 \mathrm{~nm}$ show no ferromagnetic ordering [26]. It should be noted that Lemine et al. after $40 \mathrm{~h}$ mechanical milling of commercial $\mathrm{In}_{2} \mathrm{O}_{3}$ powder (purity: $99.9 \%)$ prepared nanoparticles with crystallite size of $22 \mathrm{~nm}$ [27]. These authors use zirconia-grinding medium in order to avoid any contamination with magnetic impurities during milling. Magnetic characterization showed that such NPs became ferromagnetic at room temperature; having a saturation magnetization of $50 \mathrm{memu} / \mathrm{g}$ due to intrinsic defects induced during the milling process. Since the purity of the raw material was not shown in detail, such ferromagnetism is difficult to consider as due to $d^{0}$ only.

In this work, we focus on the interrelation between the development of RTFM and the structural and optical properties of aerosol-generated In-O NPs. Since $d^{0}$ ferromagnetism must be strongly dependent on the method of its production [28] we tried to obtain larger magnetization values in In-O nanoparticles of various sizes by using a levitation-jet generator [29]. Such technique offers many variations of the synthesis conditions, which in turn effect the RTFM of the NPs. Levitation-jet aerosol synthesis with controlled gaseous oxidizer injection in an inert gas flow allows for simultaneous manipulation of the size, shape and composition of nanoparticles generally allowing for a large-scale production of the nanopowders [30]. An important advantage of this crucible-free technique is that the metal precursor load is melted into a droplet and levitated by the action of a high-frequency electromagnetic field in the gas flow, precluding any contact with surfaces. Moreover, due to the intrinsic self-purification effects [29] the levitation-jet synthesis provides high-purity products compared with those obtained by using other types of aerosol method to synthesize In-O NPs [31,32]. This last circumstance is the most important factor for detailed magnetic studies of the NPs. We suggest that the present research provides additional clues for understanding the origin of $d^{0}$ ferromagnetism.

\section{Experimental}

\subsection{NPs synthesis conditions}

In-O aerosol-generated nanoparticles (NPs) were obtained by using a modified Gen levitation-jet generator described in detail elsewhere $[28,29]$. In this technique an indium droplet (purity: 99.999\%) was suspended in a quartz tube. The droplet was heated by an electromagnetic field $(0.44 \mathrm{MHz})$ generated using a countercurrent inductor until the levitated metal ingot began to vaporize. An adjustable stream of He gas (99.995 at.\%) blew down the vaporizing liquid droplet permanently supplied by an indium wire (purity: $99.999 \%, 1 \mathrm{~mm}$ in diameter). The rate of the vapor condensation was made equal to the rate of consumption of the metal wire [29]. The NPs formation takes place inside the condensation zone near the levitated droplet [29]. In all the experiments, special precautions were taken for providing controlled metal oxidation. A controlled amount of air (99.9 at.\%) or oxygen (99.9 at.\%) was added to the base flow in the combined mode. In this mode the oxidizers were mixed with the main gas before the levitated droplet position [29]. Some of the experiments were performed using only air as the carrier gas. All of the experiments were carried out at ambient or reduced pressure $\left(\mathrm{He}+\mathrm{O}_{2}\right)$ [33]. A strategy to control of particle size to the defined range using this approach is as follows; an average size of particles $\langle d\rangle$ is proportional to the square root from the product of the rate of consumption of the metal and molecular mass of the inert gas divided by the rate of total gas flow
[34]. Furthermore, $\langle d\rangle$ exponentially depends on the ambient gas pressure $[35,36]$ and may be controlled by the application of an electric field to the condensation zone [29]. Some aspects of evaporation-condensation mechanisms of the levitation-jet technique have been described earlier [37]. During the synthesis, prepared nanoparticles were constantly collected on the cloth filter. The resultant grey, white or grey-white powders were removed from the filter into the particle container. During the levitationjet synthesis, appropriate measures were taken in order to prevent any influence of extraneous magnetic contaminants [38].

Following on from the approach [28] all the parameters of NPs synthesis, including indium metal feed rate, helium and oxidizing gases flows rates as well as total pressure in the quartz tube are listed in Table 1 . These parameters were measured with uncertainty in the last significant digit if it was not calculated instrumentally.

\subsection{Characterization of NPS}

Particle size and morphology were studied by scanning electron microscopy (SEM) using CARL ZEISS ULTRA PLUS and LEO1450 devices and by transmission electron microscopy (TEM) using a JEOL JEM100CX II operated at $100 \mathrm{kV}$. Electron micrographs containing a total of more than 300 particles per sample were analyzed using Carl Zeiss AxioVision SE64 ver. 4.91 image processing software by an appropriate length measure to obtain Date Tables. Then size distribution of the particles, their volume average size $\langle d\rangle$ and STDEV were determined from the Date Table by using Origin Pro 2015 software [29].

Specific surface area of the nanoparticles was determined by 4point nitrogen physical sorption BET measurements using META SORBI-M device. Crystal structure of the NPs was studied by Xray powder diffractometer DRON-3M (Cu K $\mathrm{K}_{\alpha}$ radiation). Their phase composition was determined using JCPDS PDF database (release 2011) and Crystallographica SearchMatch ver. 3.102 software. Rietveld analysis (PowderCell for Windows ver. 2.4) of Xray diffraction patterns was used to evaluate the ratio of crystalline phases in the NPs. UV-vis spectra were recorded using Lambda950 (Perkin Elmer) with integrated sphere detector in the wavelength range of 200-1200 nm. Fourier transform infrared (FT-IR) spectra were recorded in the solid phase using Tensor 27 spectrometer with attenuated total reflectance accessory (Bruker) in the frequency range of $400-4000 \mathrm{~cm}^{-1}$. Raman spectra were recorded at room temperature using a Renishaw InVia Raman microscope with an air-cooled, charge coupled device. Spectra were excited with 55 microwatts of $514.5 \mathrm{~nm}$ radiation from an $\mathrm{Ar}+$ laser focused to about $2 \mu \mathrm{m}$ through a $\times 50$ objective. XPS instrument was a Thermo Scientific X-ray Photoelectron Spectrometer equipped with a monochromated $\mathrm{Al} K \alpha(1486.6 \mathrm{eV})$ source running at $72 \mathrm{~W}$ with a pass energy of $50 \mathrm{eV}$. For charge correction, a onepoint scale with the $\mathrm{C} 1 \mathrm{~s}$ peak shifted to $248.8 \mathrm{eV}$ was used. Magnetic properties of NPs were measured by means of EG\&G PARC M4500 vibrating sample magnetometer in applied magnetic fields of up to $13 \mathrm{kOe}$. This was calibrated using pure Ni standard with relative accuracy of $1 \times 10^{-3}$ at room temperature. Sample mass (a few tenths of $\mathrm{mg}$ ) was determined by a Sartorius A200 balance with relative accuracy of $\pm 2 \times 10^{-3}$. We subtracted the magnetic moment of samples from the experimental outputs of the diamagnetic contribution associated with the nylon sample containers.

\section{Results and discussion}

\subsection{NPs morphology and BET data}

Fig. 1a-c show SEM micrographs of the NPs, obtained under different synthesis conditions. In Fig. 1a, typical NPs of around 
Table 1

Main properties of In-O NPs.

\begin{tabular}{|c|c|c|c|c|c|c|c|c|c|c|c|c|c|c|}
\hline \multirow[t]{2}{*}{ Sam-ple ID } & \multicolumn{5}{|c|}{ Synthesis conditions } & \multirow[t]{2}{*}{$S, \mathrm{~m}^{2} / \mathrm{g}$} & \multirow[t]{2}{*}{$\langle d\rangle, \mathrm{nm}$} & \multirow[t]{2}{*}{$d_{\mathrm{B}}, \mathrm{nm}$} & \multirow[t]{2}{*}{$d_{\mathrm{c}}, \mathrm{nm}$} & \multirow[t]{2}{*}{$d_{\text {In, }} \mathrm{nm}$} & \multicolumn{3}{|c|}{ XRD phase composition } & \multirow[t]{2}{*}{$\sigma_{\mathrm{s}}, \mathrm{memu} / \mathrm{g}$} \\
\hline & In, g/h & $\mathrm{He}, \mathrm{l} / \mathrm{h}$ & Air, $1 / h$ & $\mathrm{O}_{2}, \mathrm{l} / \mathrm{h}$ & P, mbar & & & & & & $y$, at.\% & $a_{\mathrm{IO}}, \mathrm{nm}$ & $V_{\mathrm{In}}, \mathrm{nm}^{3}$ & \\
\hline \multicolumn{15}{|c|}{ Oxide-rich NPs ( $y>95 \%)$} \\
\hline IO5 & 25 & 0 & 75 & 0 & 1000 & $4.09 \pm 0.18$ & 240 & 250 & 52 & 32 & 99.8 & 1.012 & - & 15.0 \\
\hline IO8 & 25 & 0 & 135 & 0 & 1000 & $31.92 \pm 0.3$ & 31 & 32 & 28 & 4.6 & 99.7 & 1.011 & - & 14.1 \\
\hline IO3 & 40 & 0 & 135 & 0 & 1000 & $3.83 \pm 0.12$ & 190 & 270 & 49 & 43 & 99.6 & 1.012 & - & 43 \\
\hline IO7 & 40 & 0 & 105 & 0 & 1000 & $3.91 \pm 0.11$ & 250 & 265 & 52 & 42 & 99.6 & 1.011 & - & 6.0 \\
\hline IO10 & 7 & 1150 & 0 & 25 & 40 & $24.18 \pm 0.18$ & 40 & 42 & 29 & 7.2 & 99.5 & 1.011 & - & 6.4 \\
\hline IO9 & 50 & 1150 & 0 & 120 & 1000 & $10.93 \pm 0.1$ & 90 & 95 & 36 & 17 & 99.4 & 1.010 & - & 6.3 \\
\hline IO6 & 40 & 0 & 180 & 0 & 1000 & $5.6 \pm 0.2$ & 175 & 185 & 49 & 35 & 99.3 & 1.013 & - & 13.5 \\
\hline IO4 & 40 & 0 & 275 & 0 & 1000 & $5.23 \pm 0.08$ & 160 & 195 & 52 & 38 & 99.3 & 1.012 & - & 4.4 \\
\hline $\mathrm{IO} 2$ & 25 & 500 & 135 & 0 & 1000 & $9.76 \pm 0.04$ & 80 & 105 & 44 & 39 & 95.1 & 1.012 & 0.05214 & 27 \\
\hline \multicolumn{15}{|c|}{ Metal-rich NPs $(y<38 \%)$} \\
\hline $\mathrm{I} 17$ & 7 & 85 & 0 & 0 & 90 & $8.36 \pm 0.24$ & 50 & 110 & 20 & 85 & 37.4 & - & - & 168 \\
\hline I16 & 7 & 500 & 0 & 0 & 70 & $14.46 \pm 0.32$ & 40 & 57 & 30 & 90 & 36.2 & - & - & 90 \\
\hline I11 & 7 & 500 & 0 & 0 & 40 & $16.23 \pm 0.38$ & 140 & 51 & 32 & 44 & 35.9 & 1.009 & 0.05202 & 47 \\
\hline $\mathrm{I} 12$ & 7 & 85 & 0 & 0 & 80 & $7.99 \pm 0.22$ & 53 & 105 & 22 & 90 & 34.3 & 1.009 & 0.05196 & 72 \\
\hline I15 & 7 & 500 & 0 & 50 & 60 & $13.44 \pm 0.34$ & 44 & 62 & 23 & 56 & 27.9 & 1.012 & 0.05219 & 18.6 \\
\hline I13 & 7 & 500 & 0 & 0 & 20 & $7.41 \pm 0.12$ & 55 & 110 & 27 & 100 & 23.3 & 1.013 & 0.05215 & 10.0 \\
\hline $\mathrm{I} 14$ & 7 & 85 & 0 & 50 & 100 & $5.62 \pm 0.12$ & 125 & 150 & 20 & 135 & 22.2 & 1.010 & 0.05212 & 11.0 \\
\hline I1 & 10 & 500 & 0 & 0 & 1000 & $4.16 \pm 0.16$ & 140 & 200 & - & 200 & 1.2 & - & 0.05221 & 8.0 \\
\hline
\end{tabular}

$S$ - specific surface area.

$\langle d\rangle$ - mean particle size obtained from the micrographs.

$d_{\mathrm{B}}$ - average particle size obtained from BET measurements.

$d_{c}$ - mean crystallite size obtained from XRD data of $\operatorname{In}_{2} \mathrm{O}_{3}$ phase.

$d_{\text {In }}$ - In core size of the NPs.

$y-\mathrm{In}_{2} \mathrm{O}_{3}$ content.

$a_{\mathrm{IO}}-\mathrm{In}_{2} \mathrm{O}_{3}$ lattice parameter.

$V_{\text {In }}$ - unit cell volume of In.

$\sigma_{\mathrm{s}}-$ maximum magnetization (RT, $10 \mathrm{kOe}$ ).

$100 \mathrm{~nm}$ in size and uniform octahedral shape are shown. These NPs were obtained in $\mathrm{He}+$ air gas mixtures. The particle size distribution is moderately narrow and log-normal $[28,29]$. The observed particle shapes are the results of aggregation of oxide clusters because of predominant He cooling, similar to the case of aerosol-generated Sn-O NPs, which showed the same shapes [33]. Similar octahedral structures have been observed previous with other techniques by Hao et al. [39], Ye et al. [40], and Qin et al. [41] in $100 \mathrm{~nm}$ undoped $\mathrm{In}_{2} \mathrm{O}_{3}$ NPs; Kumar et al. [42,43], and Ramón et al. [44] in $1 \mu \mathrm{m} \mathrm{In}_{2} \mathrm{O}_{3}$ particles; Chou et al. in $50 \mathrm{~nm}$ In NPs [45]. In Fig. 1b, typical NPs are around $30 \mathrm{~nm}$ in size and octahedral or cubooctahedral (truncated) morphologies [46] are shown. Such particles are the results of predominant oxidation in the presence of a variable amount of air under the same metal feed rate [30]. Almost uniform NPs, which are seen in Fig. 1c, are tens of nanometers in size. Finally, a mix of the octahedral, rounded agglomerates with a rough surface structure [47] as well as flat [48] NPs with particle size from ten to hundreds of nm are shown in Fig. 1d. Similar morphology has been observed in the literature [49-51]. Particle size distribution in this case is rather broad with log-normal distribution function (see Fig. 1e). In Fig. 1f, a TEM micrograph of NPs I17 is presented. The particles in this image show a core-shell structure similar to those obtained by Suzuki et al. [52] and showing appropriate Moire fringes [29].

Following methods developed by Hao et al. [39] we suggested that the surface energy difference among several low-index crystallographic planes can be changed through the manipulations of some synthesis conditions. These factors may affect the chemical potentials of different crystallographic planes, change the growth rate perpendicular to these planes, and then form the different NPs morphologies. For $\mathrm{In}_{2} \mathrm{O}_{3}$ with a bcc structure, a general sequence of the surface energy of three low-index crystallographic planes is $\{111\}<\{100\}<\{110\}$ [46]. When the crystal growth rates (proportional to the surface energies) $r_{\{100\} \mid} r_{\{111\}} \approx 1.73$, perfect octahedrons appeared; when $0.87 \leq r_{\{100\}} / r_{\{111\}} \leq 1.73$, truncated octahedrons appeared [46]. Imperfect octahedrons may be attributed to several structural defects, such as oxygen vacancies $\left(V_{O}\right)$, indium vacancies $\left(V_{\text {In }}\right)$, indium interstitials $\left(\operatorname{In}_{\mathrm{i}}\right)$, oxygen interstitials $\left(\mathrm{O}_{\mathrm{i}}\right)$ and antisite defects $\left(\mathrm{O}_{\text {In }}\right)$ [39]. Perfect octahedrons were generally formed during relatively short reaction time spans (the small condensation zone [29]) and imperfect ones from larger reaction duration times. Most of the particles in Fig. 1d were shown to originate from a slow heat loss of the metal In clusters in He-based flow under reduced ambient pressure (a large-sized condensation zone).

Table 1 lists specific surface areas $(S)$ of various NPs, obtained from BET measurements (together with STDEV derived from correlation analysis of the four measurements by using the SORBI-M software) from which their average sizes $d_{\mathrm{B}}(\mathrm{nm})$, were also evaluated for ideal spherical or cubic shapes of the NPs [53]. Because of the last approach and some aggregation of the particles (see Fig. 1a-d), the $d_{\mathrm{B}}$ values are systematically larger than the morphologically estimated average volume sizes $\langle d\rangle$, obtained from the micrographs of the NPs. In following sections, we describe how the synthetic parameters affect the performance of different kind of NPs.

\subsection{X-ray diffraction analysis}

XRD patterns of NPs matched the reflections of cubic $\operatorname{In}_{2} \mathrm{O}_{3}$ JCPDS 06-0416 with unit-cell parameters $a=1.009-1.013 \pm 1 \mathrm{~nm}$ (see Table 1). The second crystal phase of NPs matched the XRD patterns of tetragonal In JCPDS 85-1409 with unit-cell parameters $a=0.3248-0.3252 \pm 1 \mathrm{~nm}$ and $c=0.4926-0.4942 \pm 1 \mathrm{~nm}$. No other crystal phases were found in our NPs by XRD. Fig. 2 shows representative patterns of NPs related with the above-mentioned micrographs. Rietveld analysis of the $\operatorname{In}_{2} \mathrm{O}_{3}$ phase percentages $y$ and its lattice parameter for all the NPs are presented in Table 1. It is seen that the $\mathrm{In}_{2} \mathrm{O}_{3}$ lattice parameter generally increases with oxygen ratio in the total gas flow during NPs production.

It should be noted that to our knowledge, no NPs composed from both crystalline In and $\operatorname{In}_{2} \mathrm{O}_{3}$ phases simultaneously were previously observed in the In-O system. Earlier, a film composed 

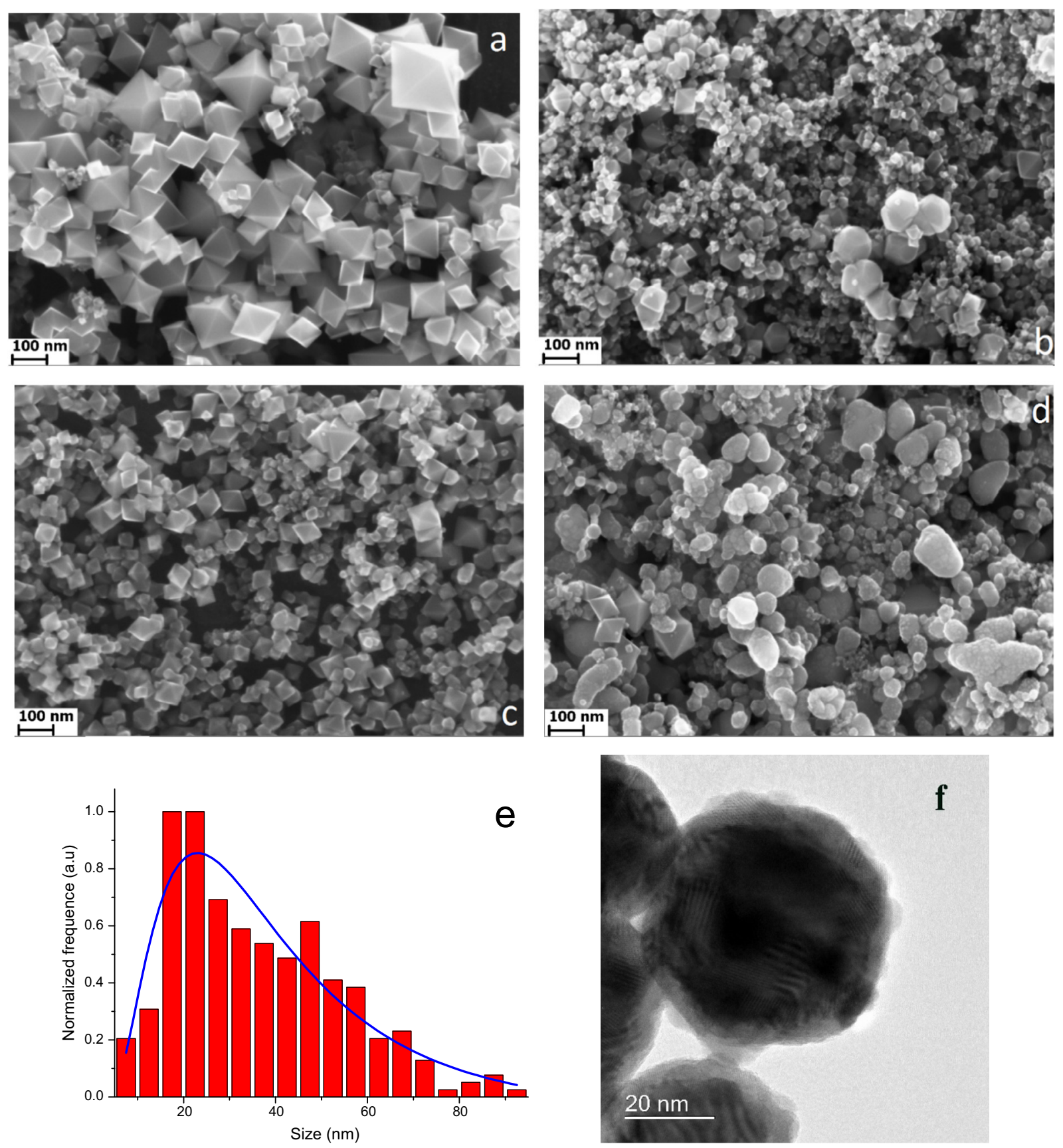

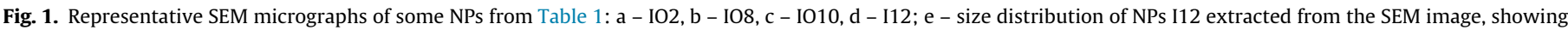
the fit to a log-normal distribution function (STDEV $=25 \mathrm{~nm}$ ), and $\mathrm{f}$-TEM micrograph of NPs I17.

of In/ $/ \mathrm{InO}_{\mathrm{x}}$ structured nanoparticles with indium crystal core and amorphous indium oxide shell was obtained by magnetronsputtering and natural oxidation [54]. Sputter deposition of indium in ionic liquids could produce stable In metal nanoparticles whose surface was covered by an amorphous $\mathrm{In}_{2} \mathrm{O}_{3}$ layer to form $\mathrm{In} / \mathrm{In}_{2} \mathrm{O}_{3}$ core/shell particles [52]. The TEM image shown in Fig 1f shows the existence of a core-shell structure in the NPs produced here. The metallic In core sizes of the NPs $\left(d_{\text {In }}\right)$ should be evaluated as $d_{\text {In }} \approx d_{\mathrm{B}}(1-y)^{1 / 3}$.

Crystallite sizes, $d_{c}$, of outer $\operatorname{In}_{2} \mathrm{O}_{3}$ phase in the NPs were determined by using Scherrer equation for a coherent scattering region:

$d_{c} \approx \lambda /\left(\beta_{400} \cdot \cos \theta\right)$

where the wavelength is $\lambda=0.1542 \mathrm{~nm}, \beta_{400}$ is full width at half maximum (FWHM) for 400 peak (in radians), $\theta$ is the Bragg angle. $d_{c}$ is usually smaller than the size of NPs identified by electron microscopy, because the coherent scattering region of the crystal phase corresponds to the inner ordered region of a particle, and it does not include severely distorted boundaries including interfaces.

For convenience of the further investigations, all the obtained NPs are divided in two sets, depending on the $\operatorname{~n}_{2} \mathrm{O}_{3}$ content: oxide-rich nanoparticles $(y>95 \%)$ and metal-rich ones $(y<38 \%)$.

\subsection{Magnetic measurements}

VSM magnetic measurements show that all the NPs have ferromagnetic hysteresis loops at room temperature. Some of measurement results of magnetization $\sigma v$ s. applied magnetic field $H$, are shown in Fig. 3. All the loops exhibit soft-magnetic behavior with coercivity between $30-140$ Oe. In Table 1 one of the basic 


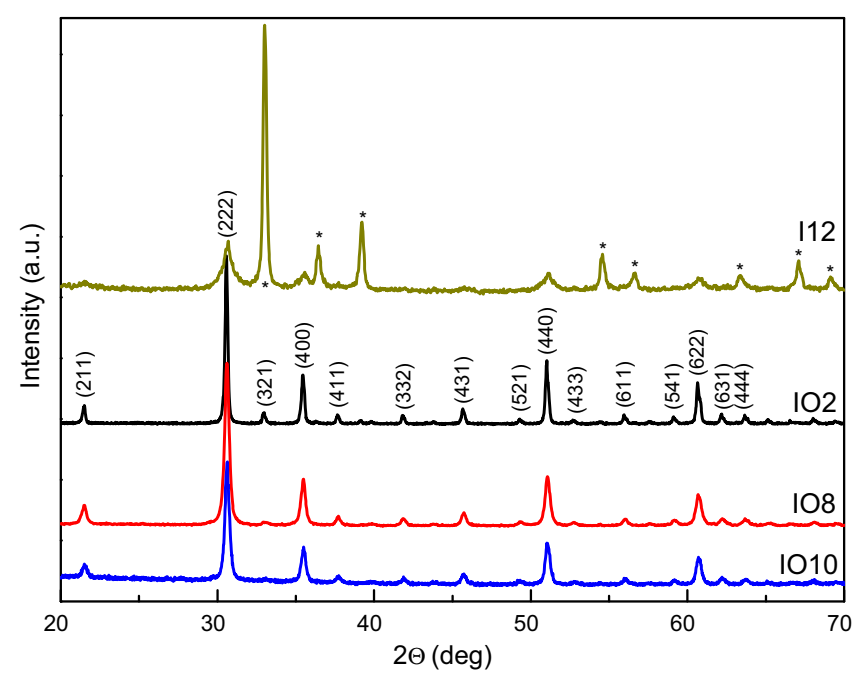

Fig. 2. XRD patterns of typical NPs. The numbers of curves correspond to the numbers of NPs in Table 1. Asterisks mark the reflections from In (JCPDS 85-1409). Indexed reflections are belong to $\mathrm{In}_{2} \mathrm{O}_{3}$ JCPDS 06-0416.

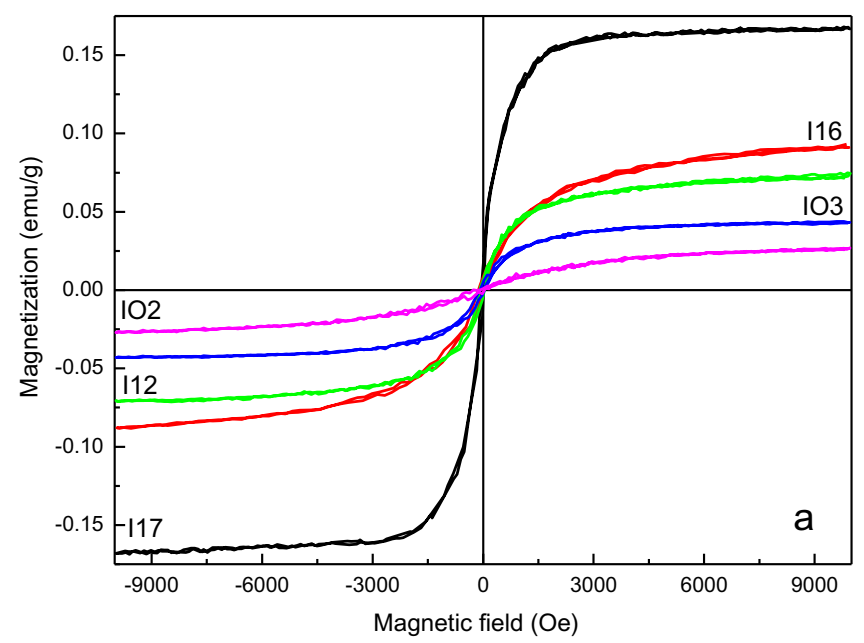

Fig. 3. Ferromagnetic hysteresis loops of some NPs from Table 1 . The numbers of curves correspond to sample IDs of NPs from Table 1.

characteristics of hysteresis loops - net maximum specific magnetization $\sigma_{\mathrm{s}}$ (at $H=10 \mathrm{kOe}$ ) is presented. The data in Fig. 3 are plotted after correcting the diamagnetic contributions from magnetic susceptibilities of bulk In and $\mathrm{In}_{2} \mathrm{O}_{3}$ [19] $\left(-2 \times 10^{-7} \mathrm{~cm}^{3} / \mathrm{g}\right.$ and $-5 \times 10^{-7} \mathrm{~cm}^{3} / \mathrm{g}$, respectively [55]). The highest maximum magnetization obtained in our NPs is about $0.17 \mathrm{emu} / \mathrm{g}$ (I17). This value was found to be above one order of magnitude higher in comparison to the above-mentioned value reported for undoped $11 \mathrm{~nm}$ $\mathrm{In}_{2} \mathrm{O}_{3}$ NPs [19] and exceeded the maximum value achieved in the indium oxide film [22].

Despite many efforts, there is still an incomplete understanding of the origin RTFM in $d^{0}$ magnetic materials [56]. Due to that, the main aim of our study was to find out whether the maximum magnetization of NPs depends on the other features of the NPs $[7,33,57]$.

As is seen from the previous paragraphs (including the data from Table 1), there are no obvious dependencies of maximum magnetization from the morphology, mean particle sizes, real phase compositions as well as an oxygen content. Probably, it is related to the fact that all the above-mentioned characteristics of NPs are affecting the RFTM independent manners [28]. This

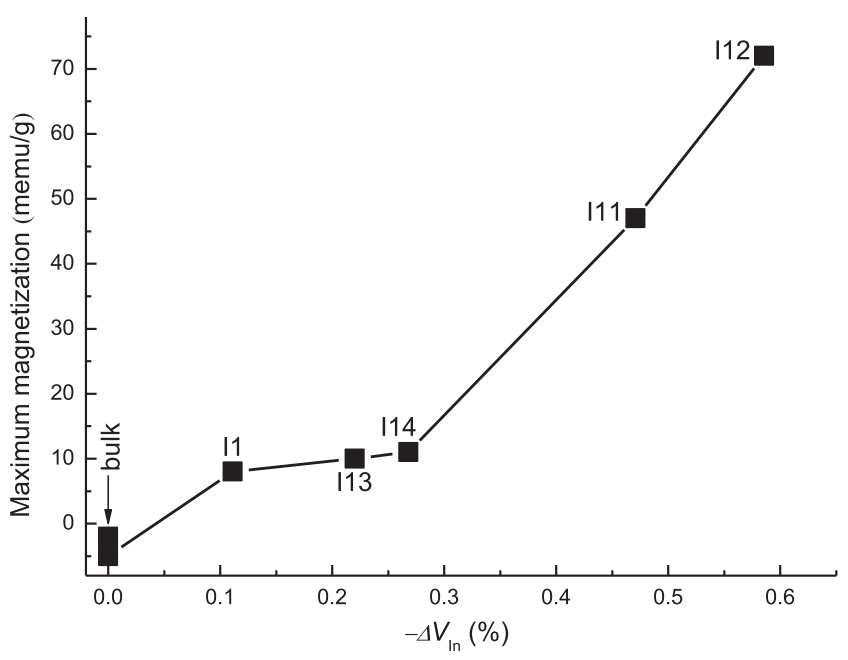

Fig. 4. Maximum magnetization $\sigma_{\mathrm{s}}(\mathrm{memu} / \mathrm{g})$ values $v s$. the change in metal In unit cell volume of some NPs.

suggestion explains the difference between magnetic properties of our samples. It is known that the maximum $d^{0}$ magnetization can be achieved up to a specific vacancy concentration. Beyond it, the magnetization will reduce and eventually vanishes [58]. As expected, the magnetic order was found only in the samples, in which a vacancy density of several percent was achieved [59]. This density is necessary to get magnetic order in solids, independently of the details of the structure or elements that are presenting in the lattice provided that the vacancies or other defects in the lattice lead to nearly localized magnetic moments [58]. In Fig. 4, we can see a pronounced descending behavior of maximum magnetization from the metal In unit cell volume of some NPs. Such behavior points out the main role of interface area between In and $\operatorname{In}_{2} \mathrm{O}_{3}$ lattices in the $d^{0}$ ferromagnetism of In-O NPs similarly to that seen in the $\mathrm{Zn}-\mathrm{O}$ and $\mathrm{Sn}-\mathrm{O}$ cases $[7,33,57]$.

In order to find out other possible relationships between the observed room temperature ferromagnetic ordering and defects in the In-O structures on the NPs surface, an optical spectroscopic technique was used.

\subsection{Optical characterization of NPS}

\subsection{1. $U V$-vis reflectance spectra}

UV-vis diffuse reflectance $(R)$ spectra of two sets of NPs at RT are shown in Fig. 5 over the wavelength range of $200-850 \mathrm{~nm}$. Large dips in the reflectances at wavelengths $\lambda<350 \mathrm{~nm}$ take place near the fundamental absorption edge of $\operatorname{In}_{2} \mathrm{O}_{3}$ for the oxide-rich NPs. Similar behavior of reflectance was earlier observed in undoped $\mathrm{In}_{2} \mathrm{O}_{3}$ NPs $[26,60,61]$. For the metal-rich NPs the dips are smoother and less intense.

It is interesting to follow some changes of reflectance behavior in the UV $(\lambda=200 \mathrm{~nm})$ and NIR $(\lambda=1200 \mathrm{~nm})$ regions for the different NPs. In metal-rich NPs (Fig. 5b), UV and NIR-reflectances decrease with $y$ (except for the NPs I13 and I15, probably, because of a weak confinement effect). We are suggesting, that a lower oxide content enables more free electrons from the metal core to become available, and because of that, the amount of light, reflected from such NPs, increases. For oxide-rich NPs in the NIRregion, a large heat loss in the semiconductor must take place due to free carriers inside the band gap and so the reflectance should decreased. Fig. 6 demonstrates those dependencies as a plot of $R v s$. indium core size for all the NPs. As seen in Fig. 6, a similar behavior of the reflectance and maximum magnetization $v s$. the value of metal surface also takes place. This observation 

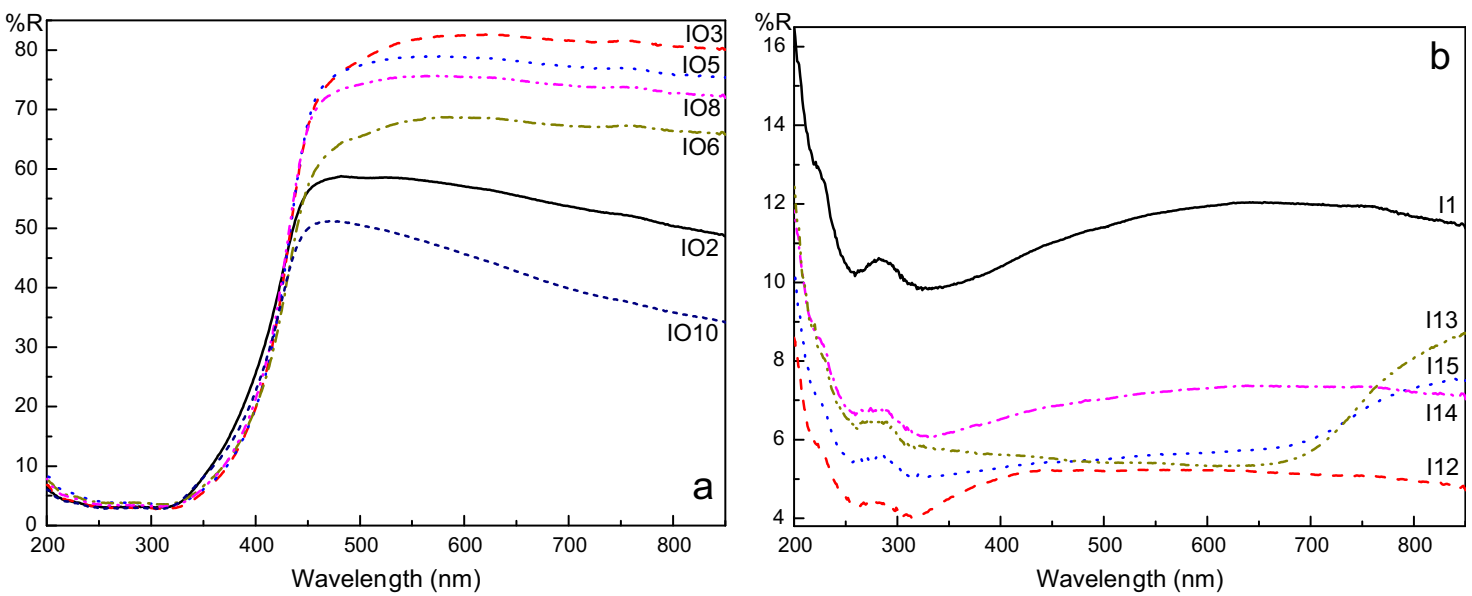

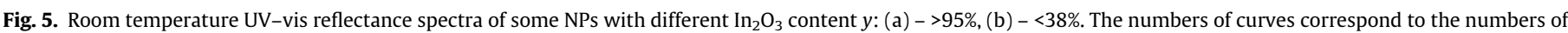
NPs in Table 1.

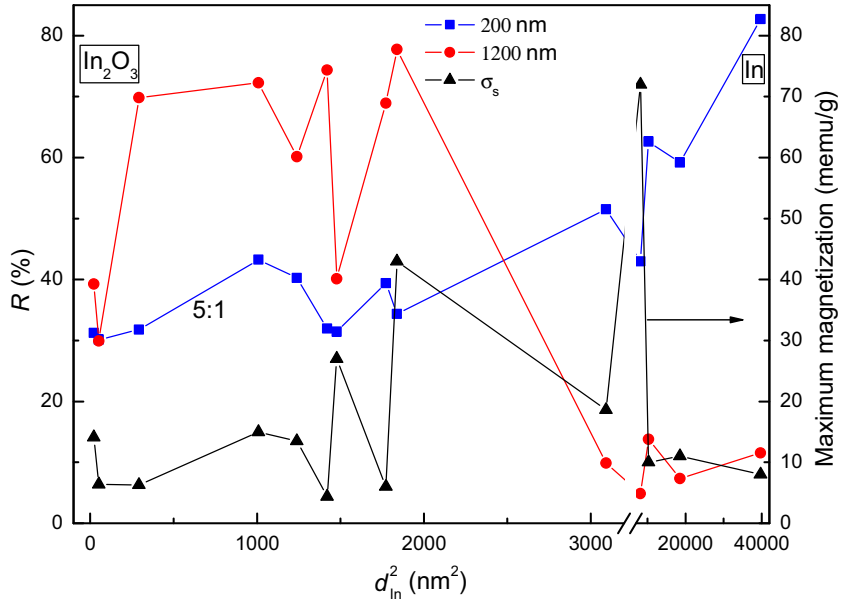

Fig. 6. NPs reflectance at UV and NIR regions, and $\sigma_{\mathrm{s}} v s$. indium core size.

emphasises the above-mentioned role of oxide/metal interface in the origin of RTFM. In the NPs with maximum $\sigma_{\mathrm{s}}$, large amounts of charged species are presented at the energy levels of local vacancies, which lie below the upper edge of the fundamental band gap. For the other NPs, $\sigma_{s}$ has not reached its maximum, which may be due to lack of oxygen vacancies or excess of In ions presented at the $\mathrm{In} / \mathrm{In}_{2} \mathrm{O}_{3}$ interface.

To study the energy band gap structure of our composite NPs, their reflectance spectra were at first analyzed using KubelkaMunk equation $F(R)$ [62], which is related to the diffuse reflectance as follows:

$F=(1-R)^{2} / 2 R$

Here, $R$ is the absolute reflectance and $F$ is equivalent to the absorption coefficient $\alpha$.

The optical band gap energy ( $\left.E_{\mathrm{g}}\right)$ may be calculated from $\alpha$ by a Tauc's plot using Tauc relation [63]:

$\alpha h v=A\left(h v-E_{g}\right)^{q}$

where $A$ is a constant, which depends from the transition probability, $h v$ is the energy of an incident photon, and $q$ is an index, which characterizes an optical absorption process in a semiconductor ( $q$ equals 0.5 for the direct band gap and 2 for the indirect one). The direct band gap of bulk $\mathrm{In}_{2} \mathrm{O}_{3}$ was long thought to be $\sim 3.75 \mathrm{eV}$ from the onset of significant optical absorption, with a low-intensity onset of absorption below this energy, which are attributed to indirect optical transitions $[64,65]$.

Direct band gap $E_{\text {gd }}$ of the oxide-rich NPs was estimated by plotting $(F h v)^{2}$ as a function of light wave energy $h v$ (Fig. 7a). Indirect band gap $E_{\mathrm{gi}}$ for the same NPs was estimated by plotting $(F h v)^{0.5}$ as a function of $h v$ (Fig. 7b). Fig. 7c shows possible determination of the direct optical band gaps for the metal-rich NPs. The linear portions of all the curves were extrapolated to zero in order to estimate these band gap values.

All the estimated $E_{\mathrm{g}}$ s for the NPs (based on the data of Fig. 7 a-c) are listed in Table 2 together with their corresponding $\sigma_{\mathrm{s}}$ values. The direct band gap $\left(E_{\mathrm{gd}}\right)$ values of almost oxide-rich NPs varied in the range of $3.47-3.67 \mathrm{eV}$. These values are close to the earlier observed ones for the $\operatorname{In}_{2} \mathrm{O}_{3}$ NPs $[44,66,67]$. The indirect band gap values $E_{\mathrm{gi}}$ of such NPs varied in the range of $2.65-2.72 \mathrm{eV}$, which are close to the values measured by Weiher et al. [64]. The weak nature of optical absorption around this energy may be attributed to transitions between the highest valence-band states and states at the conduction-band minimum, being dipole forbidden nor having only minimal dipole intensity [65]. For the NPs with large indium content, $E_{\text {gd }}$ values vary between 2.05 and $3.11 \mathrm{eV}$. In Fig. 7c, a pronounced composite structure of the NPs with multiple energy levels near the edge of the fundamental band gap may be seen. As listed in Table 2, $\sigma_{\mathrm{s}}$ demonstrates no definite dependence from $E_{g}, S$ values, for NPs I12 (with one of the maximum value of $\sigma_{\mathrm{s}}$ ), whereas $E_{\mathrm{gd}}$ for the two components is the same. It should be emphasized that there will be equal input of defect area of the both sides of the $\mathrm{In} / \mathrm{In}_{2} \mathrm{O}_{3}$ interface in the possible core-shell structure of our NPs.

\subsubsection{FT-IR spectra}

FT-IR spectra for the oxide-rich NPs in the wavenumber region of 400-1300 $\mathrm{cm}^{-1}$ are shown in Fig. 8a. It is known that absorption bands below $1000 \mathrm{~cm}^{-1}$ in metal oxides are normally due to the interatomic vibrations, and additional peaks, obtained above the $1000 \mathrm{~cm}^{-1}$ may be due to the overtones [26]. Three intense peaks located between 615 and $505 \mathrm{~cm}^{-1}$ were observed, some of which are characteristic of the cubic $\operatorname{In}_{2} \mathrm{O}_{3}$ phase [60]. In order to determine any changes in the bands positions of the different NPs, IR measurements in the above-mentioned region were undertaken and the results are shown in Fig. 8b. In that figure, the characteristic peaks of $\operatorname{In}_{2} \mathrm{O}_{3}$ are split into three bands centered at 596, 561, and $538-534 \mathrm{~cm}^{-1}$, respectively. The peak positions are very close to some of the peaks positions observed by other authors $[25,26,68]$. 

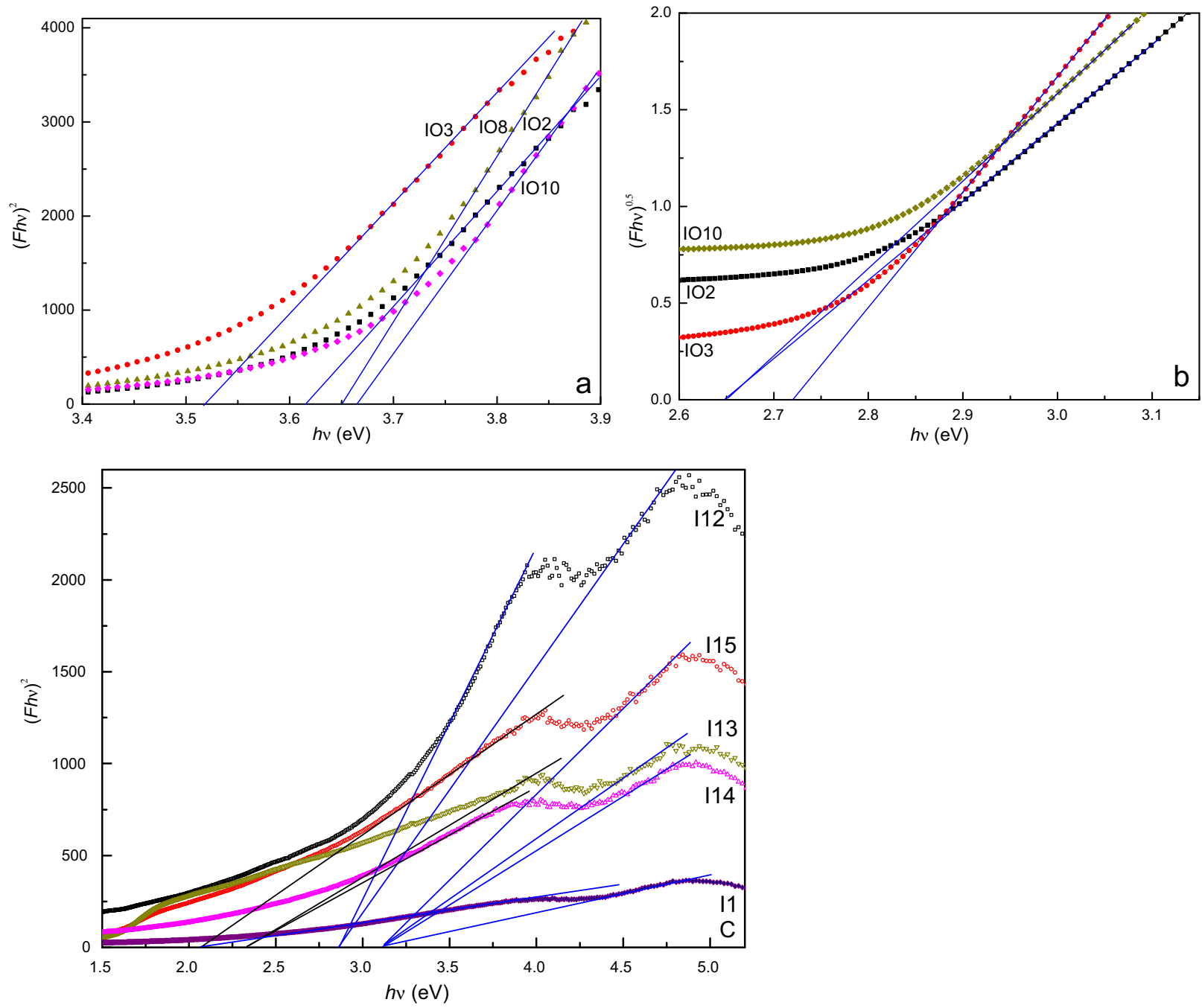

Fig. 7. Tauc plots of $(F h v)^{1 / q} v s$. $h v$ of some oxide-rich $(\mathrm{a}, \mathrm{b})$ and metal-rich (c) NPs for different $q: \mathrm{a}, \mathrm{c}-2 ; \mathrm{b}-0.5$. The numbers of curves correspond to the numbers of NPs in Table 1.

Table 2

Basic UV-vis properties of some NPs.

\begin{tabular}{llll}
\hline Sample ID & $E_{\mathrm{gd},} \mathrm{eV}$ & $E_{\mathrm{gi},} \mathrm{eV}$ & $\sigma_{\mathrm{s}}, \mathrm{memu} / \mathrm{g}$ \\
\hline IO5 & 3.47 & 2.72 & 15.0 \\
IO8 & 3.65 & 2.69 & 14.1 \\
IO3 & 3.52 & 2.72 & 43 \\
IO7 & 3.52 & 2.72 & 6.0 \\
IO10 & 3.67 & 2.65 & 6.4 \\
IO9 & 3.64 & 2.70 & 6.3 \\
IO4 & 3.52 & 2.70 & 4.4 \\
IO6 & 3.51 & 2.68 & 13.5 \\
IO2 & 3.62 & 2.65 & 27 \\
I11 & - & - & 47 \\
I12 & 2.86 & - & 72 \\
I15 & $3.12 ; 2.07$ & - & 18.6 \\
I13 & $3.12 ; 2.33$ & - & 10.0 \\
I14 & $3.12 ; 2.33$ & - & 11.0 \\
I1 & $3.12 ; 2.07$ & - & 8.0 \\
\hline
\end{tabular}

$E_{g d}$ and $E_{g i}-$ direct and indirect band gap values.

According to the previous literature results, the band at 566$557 \mathrm{~cm}^{-1}$ is attributed to In-O stretching whereas the bands at $607-600 \mathrm{~cm}^{-1}$ are the characteristic of In-O bending vibrations $[51,60,68-70]$. Inside the band at $538-534 \mathrm{~cm}^{-1}$ slight changes in the peak positions takes place. Although no obvious correlations between the peak parameters and $\sigma_{\mathrm{s}}$ were found, small red shifts of the peak positions in the last IR-band for NPs with large maximum magnetization values could be noted. It is also interesting, that in our NPs the strong peaks, observed previously in the literature in the region of $414-490 \mathrm{~cm}^{-1}$ are attributed to In-O stretching in cubic $\mathrm{In}_{2} \mathrm{O}_{3}$, and are very weak modes. At the same time, in the IR spectra of metal-rich NPs, (Fig. 9), such peaks are pronounced, although the rest of the regions demonstrated no obvious peak structure.

From the UV-vis and FT-IR studies the small changes in both band gap and bonding might be influenced by defects during the formation of $\mathrm{In}_{2} \mathrm{O}_{3}$ lattice [26]. A minor variation in their frequencies or relative intensities occurs in different ${\operatorname{~}{ }^{3+}}^{3+}$ distributions in the interstitial sites. As it is known they are very sensitive to the oxygen vacancies and other defects [60].

\subsubsection{Raman spectra}

Cubic $\mathrm{In}_{2} \mathrm{O}_{3}$ belongs to the space group $I_{a} 3 / T_{h}{ }^{7}$, having: 22 Raman active modes ( $A_{\mathrm{g}}, E_{\mathrm{g}}$ and $T_{\mathrm{g}}$ symmetry), 16 infrared active modes ( $T_{\mathrm{u}}$ symmetry) and 10 inactive modes ( $A_{\mathrm{u}}$ and $E_{\mathrm{u}}$ symmetry) in both infrared and Raman spectra [71,72]:

$\Gamma=4 A_{g}+4 E_{g}+14 T_{g}+5 A_{u}+5 E_{u}+16 T_{u}$

Room temperature Raman spectra of the NPs were recorded in the $100-700 \mathrm{~cm}^{-1}$ range (Fig. 10). The Raman spectrum of the 

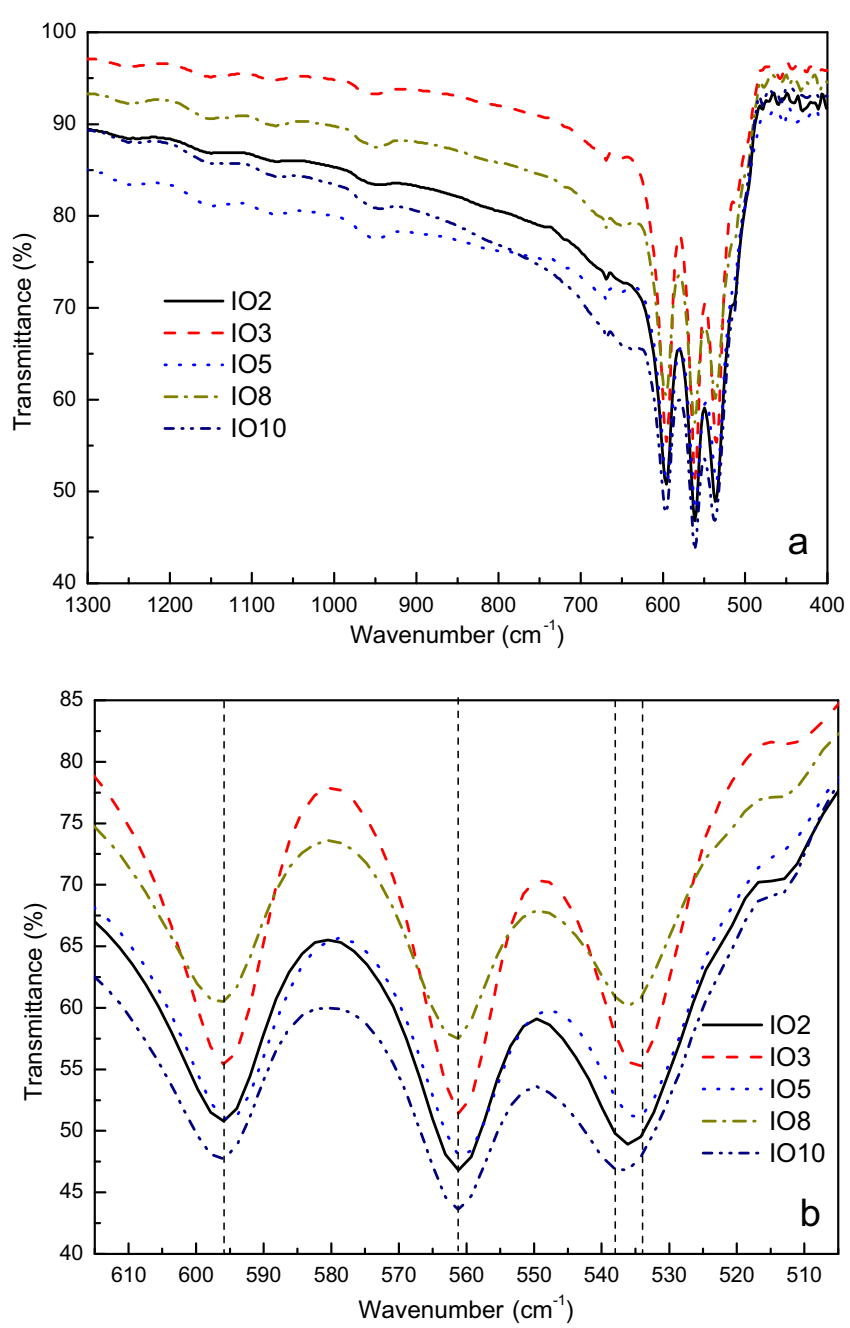

Fig. 8. IR bands of some oxide-rich NPs in the range of: $1300-400 \mathrm{~cm}^{-1}$ (a); 615 $505 \mathrm{~cm}^{-1}$ (b). The numbers of curves correspond to the numbers of NPs in Tables 1.

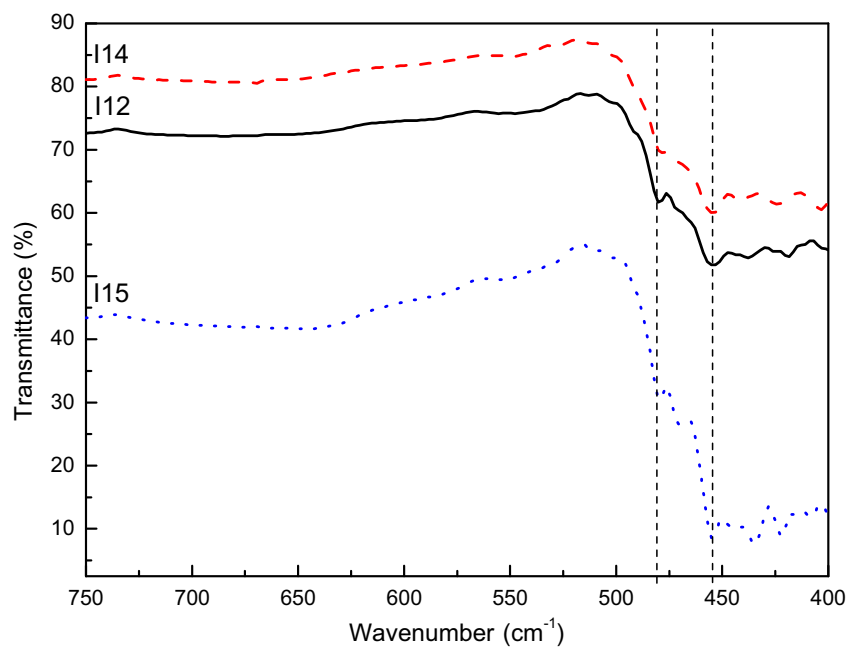

Fig. 9. IR bands of some metal-rich NPs in the range of $750-400 \mathrm{~cm}^{-1}$. The numbers of curves correspond to the numbers of NPs in Tables 1.

oxide-rich NPs revealed 16 vibrational modes (Fig. 10a, NPs IO5). The bands around 111, 155, 213, 308, 368, 393, 454, 469, 519, 547 , and $630 \mathrm{~cm}^{-1}$ have $T_{\mathrm{g}}$ symmetry. The bands at 133,310 , and
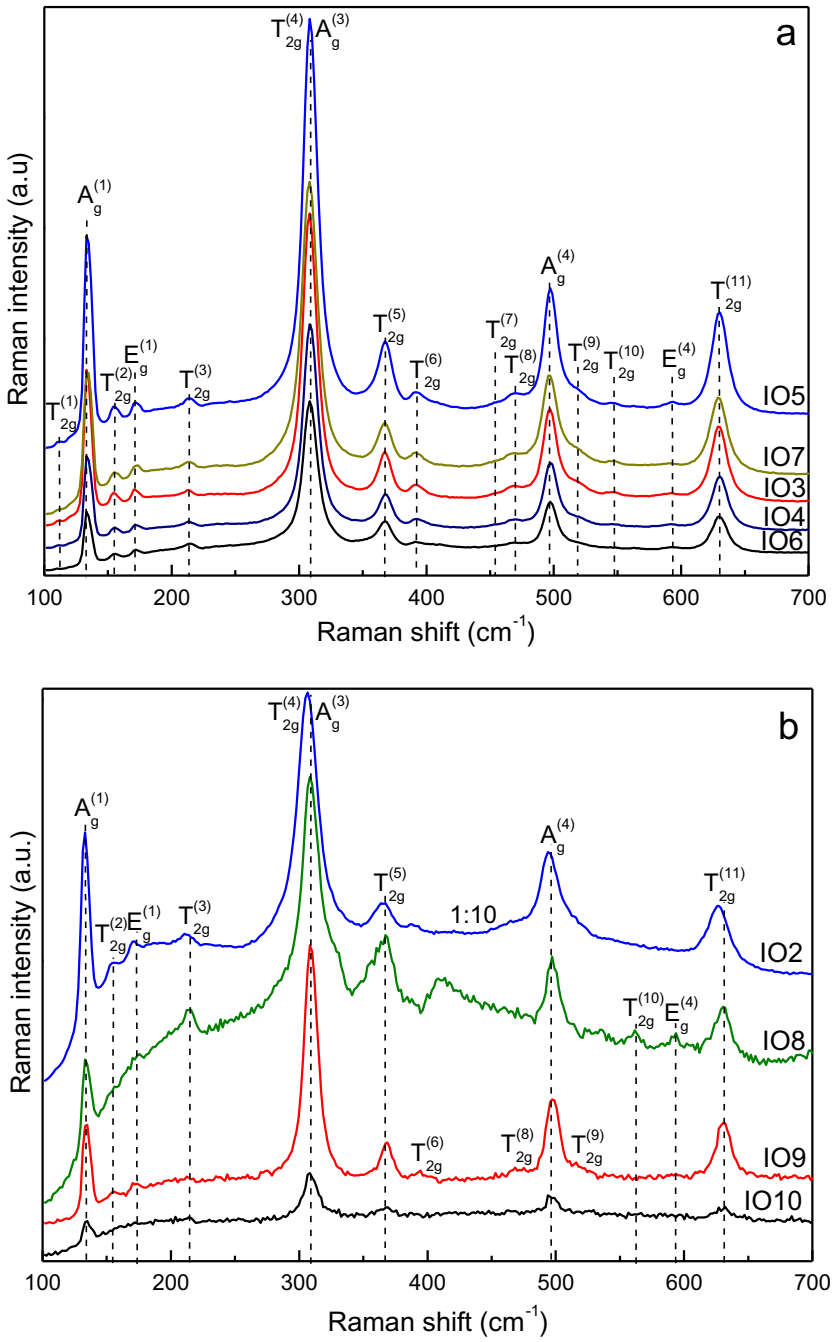

Fig. 10. a and b. Raman spectra of some oxide-rich NPs. The numbers of curves correspond to the numbers of NPs in Table 1. The Raman spectra are vertically shifted for clarity.

$497 \mathrm{~cm}^{-1}$ have $A_{\mathrm{g}}$ symmetry and the bands at 171 , and $593 \mathrm{~cm}^{-1}$ have $E_{\mathrm{g}}$ symmetry [44,73]. All the above-mentioned bands are assigned to the phonons associated with the bcc-structured indium oxide [71].

For the large-sized NPs IO5, IO7, IO3, IO4, and IO6 $\left(d_{\mathrm{B}}>120 \mathrm{~nm}\right)$, the intensity of these vibrational modes correlates with $\operatorname{In}_{2} \mathrm{O}_{3}$ content $y$. As seen from Fig. 10a and Table 1, NPs with the same $y=99.6$ at.\% (IO3 and IO7), and $y=99.3$ at.\% (IO4 and IO6) and closed values of $d_{\mathrm{B}}$ demonstrated similar Raman peak positions and intensities, despite the fact that their maximum magnetizations are essentially different.

For smaller-sized oxide-rich NPs IO2, I08, IO9, and IO10 $\left(d_{\mathrm{B}}<120 \mathrm{~nm}\right)$ the situation is more complicated (Fig. 10b). For NPs IO2 $\left(d_{\mathrm{B}}=105 \mathrm{~nm}\right)$ with $y=95.1 \%$, the intensity of Raman bands is decreased too, but most of the major Raman bands shift towards the lower energy side and some small peaks disappeared. Despite the smallest size seen in the study the NPs IO8 $\left(d_{\mathrm{B}}=32 \mathrm{~nm}\right)$ had Raman peaks that were pronounced, because of the large $y$ value. As seen in the larger specific surface could provoke the intensities of the vibrational modes of NPs to decrease, due to structural changes introduced by disorder and size reduction [44], the $\sigma_{s}$ value of the last NPs is lower than previous one. Despite the mean particle size of NPs IO9 being twice that of IO10 (as for the previous couple), their maximum magnetizations have the same values. 


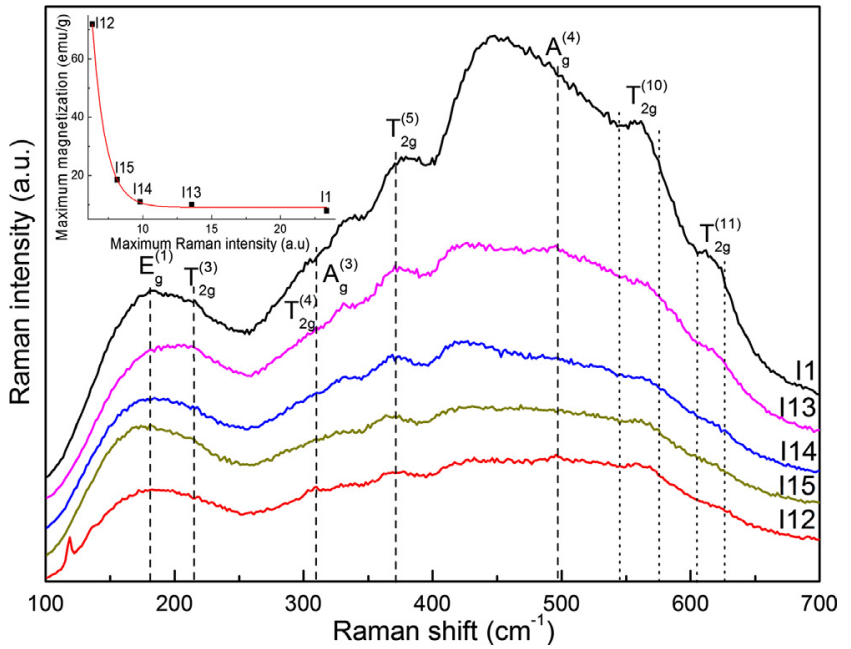

Fig. 11. Raman spectra of some metal-rich NPs. The numbers of curves correspond to the numbers of NPs in Table 1. The Raman spectra are vertically shifted for clarity. Inset - an exponential dependence of $\sigma_{\mathrm{s}} v s$. maximum intensities of the Raman spectra.

Moreover, the Raman peak at $308 \mathrm{~cm}^{-1}$ corresponds to the stretching mode of the indium oxide and is very sensitive to the presence of oxygen vacancies [71]. Thus, the observed asymmetry of this mode in NPs IO8 could be attributed to the oxygen vacancies [42].

For the metal-rich NPs, Raman spectra are much weaker, but the band structure is still resolvable (Fig. 11). These spectra looks like the Raman spectra observed by Prakash et al. in $\mathrm{ca} .10 \mathrm{~nm}$ spherical $\mathrm{In}_{2} \mathrm{O}_{3}$ NPs [18], which point to the similar surface structure for both types of NPs. The maximum degree of degeneration takes place for NPs I12 with the maximum of $\sigma_{\mathrm{s}}$ value. The dependence of maximum magnetization with maximum intensity of the corresponding Raman spectra demonstrates an exponential behavior (inset in Fig. 11).

The increase in intensity of Raman spectra in the metal-rich NPs, accompanied by an enhancement in $\sigma_{s}$, is apparently related to an increase in the amount of metal and oxygen defects at the In/ $\mathrm{In}_{2} \mathrm{O}_{3}$ interface. This phenomenon is in concordance with our UVvis data. Therefore, Raman spectra are pointing out the predominant role of ions vacancies, which may be responsible for the RTFM origination in NPs.

Thus, the lattice distortion is mainly caused by the interstitial oxygen ions as they occupy oxygen vacancy $\left(\mathrm{V}_{\mathrm{O}}\right)$ sites, which are generally empty in pure $\mathrm{In}_{2} \mathrm{O}_{3}$ [44]. To verify this situation we use the XPS technique.

\subsection{XPS component analysis of the NPS}

X-ray photoelectron spectroscopy analysis was performed on the different oxide-rich and metal-rich NPs in order to understand the chemical composition and defect state of the material. The survey scans of all the "as is" NPs showed distinguished peaks only for indium, oxygen and carbon. In Fig. 12 the different peaks regions of the survey spectra of some NPs, identified by using CasaXPS v. 3.17 software [74], are presented. It should be noted that no magnetic impurities or other chemical elements was found during XPS scanning, supporting the idea that RTFM is not due to magnetic impurities $[75,76]$. There are obvious difference in the element peak intensities among the above-mentioned sets of our NPs.

As an example, the high-resolution XPS spectra for the different regions of NPs I17 with large maximum magnetization are shown in Fig. 13. The XPS peaks were fitted with the Origin 2015 software by using Gaussian profile function, including fixed XPS baseline

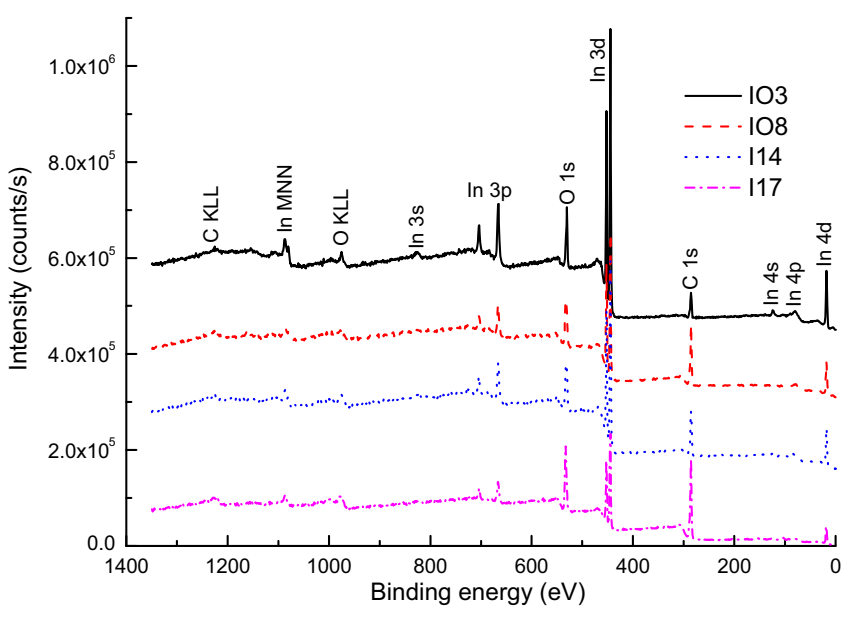

Fig. 12. Survey XPS spectra from some oxide-rich and metal-rich NPs. The numbers of curves correspond to the numbers of NPs in Tables 1. The XPS spectra are vertically shifted for clarity.

mode in Shirley computation range method and fixed all the peaks widths [77]. The determined values of binding energy (BE), FWHM, and areas of all the fitted components of some NPs are listed in Table S1 (See Appendix A. Supplementary data).

It is known, that with the XPS method it is important to check out that only one line appears in the $C 1 \mathrm{~s}$ range; if there is more than one, the other effects (e.g. surface charging) must be involved [78]. In our NPs residual amounts of adventitious carbon, carbonyl, etc. were unavoidable due to their exposure to air [7], so the surface charging effects were diminished using the BE shifts calibrated keeping with $C 1$ s position fixed at $284.8 \mathrm{eV}$ [74,79-81]. Highresolution $\mathrm{C}$ 1s spectrum was shown in Fig. 13a and the broad energy range from $282 \mathrm{eV}$ to $290 \mathrm{eV}$ may be observed. The main peak, corresponds to carbon contamination (C-C bonds [80]), was observed at $284.8 \mathrm{eV}$. The other weak peaks were located at $286.3 \mathrm{eV}$ and $288.6 \mathrm{eV}$ and were characteristics of the oxygen bound species with $\mathrm{C}-\mathrm{O}$ bonds, as well as $\mathrm{C}=\mathrm{O}$ bonds, respectively [81].

For the high-resolution in the In $3 \mathrm{~d}$ region, a perfect fit to two peaks, located at binding energies 444.6 and $452.1 \mathrm{eV}$, are clearly observed in Fig. 13b, which can be attributed to the characteristic spin-orbit split In $3 d_{5 / 2}$ and In $3 d_{3 / 2}$, respectively $[79,82,83]$. This result indicates that the surface indium valence is mainly +3 in the NPs [84], suggesting the $\operatorname{In}_{2} \mathrm{O}_{3}$ phase (In $3 \mathrm{~d}_{5 / 2}$ peaks positions in indium metal: 443.1-444.3 eV, $\mathrm{In}_{2} \mathrm{O}_{3}$ : 444.5-444.9 eV) [75,85,86]. As seen from Table S1 for the metal-rich NPs, these peaks are slightly shifted towards higher energy from the binding energies of pure indium metal $(\operatorname{In} 0)$, but agreed with those of $\operatorname{In}_{2} \mathrm{O}_{3}$. Suzuki et al. found similar situation for core/shell-structured particles composed of a single-crystalline In metal core and amorphous $\mathrm{In}_{2} \mathrm{O}_{3}$ shell layer [52]. Li et al. observed the In $3 \mathrm{~d}_{5 / 2}$ XPS BEs at $444.3 \mathrm{eV}$ and $443.7 \mathrm{eV}$ for the as-prepared and $\mathrm{Ar}$ ion sputtered In NPs, respectively [87]. They attributed the XPS results to the surface oxidation of indium metal, which was consistent with their XRD and XPS results [88]. In our case, according to Auger In MNN peak plots (Fig. 13c), it is obvious, that these peaks for the samples with maximum amount of oxide (IO5) and metal (I1) are practically the same in terms of their shapes and similar to the shape of pure In oxide [89]. This suggests that all the particles in both particle size distributions were oxidized through their surface, rather than an array of separated metal and oxide particles. Together with our XRD data, that proves the existence of coreshell structure in our NPs.

An analysis of In 3d core level plots for the NPs IO5 and I1 shows that the position of In $3 \mathrm{~d}_{5 / 2}$ peak for the metal-rich NPs does not fall into the above-mentioned area of BEs of In metal, but is located 

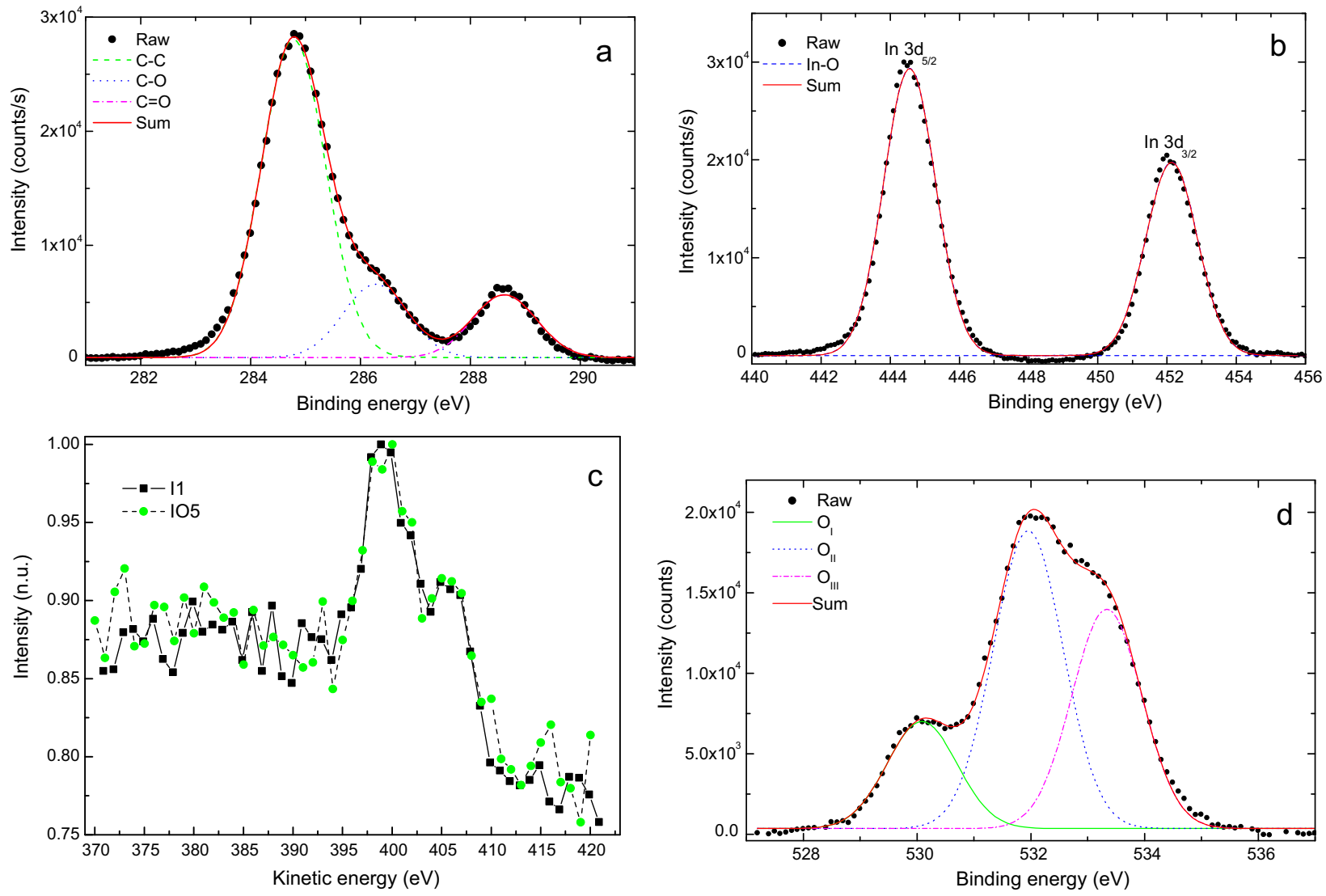

Fig. 13. High-resolution XPS spectra of NPs I17 in the core level regions: (a) C 1s, (b) In 3d, (d) O 1s. (c) Auger In MNN peak plots for NPs IO5 and I1.

in the area belonging to the $\operatorname{In}_{2} \mathrm{O}_{3}$. Similar behavior for FWHM of this peak was also observed. None of that agrees with certain XPS data for the pure In metal and pure In oxide [89]. This situation also confirms the surface oxidation of all the NPs under our study. At the same time, the lack of correlation between our XPS and XRD data (because of different sampling depths) indicates that existence of the RTFM in our NPs is not associated with perfection degree of the outer layer of the NPs shell. Probably, it originated from the some peculiarities of an inner core-shell interface because of mutual diffusion of In and $\mathrm{O}$ ions from the surface and volume of NPs. That supports the existence of oxidized shell in our NPs [88].

In order to understand this situation, it is necessary to look insight the XPS data of the O 1s core level of our NPs. As it is shown in Fig. 13d, a strongest asymmetric peak was observed in this region. The asymmetrical XPS for 01 s could be described by three sub-bands divided by the symmetric Gaussian peaks labelled as $\mathrm{O}_{\mathrm{I}}$, $\mathrm{O}_{\text {II }}$, and $\mathrm{O}_{\text {III }}$ in Fig. 13d [90-95].

The first peak - $\mathrm{O}_{\mathrm{I}}$, with maximum at $530.1 \mathrm{eV}$ [96], corresponds to the bulk crystal lattice oxygen. This peak was assigned to the $\mathrm{O}^{2-}$ ions in the tetrahedral interstices of the face-centered cubic In $^{3+}$ lattice $[84,91,97]$. It originates from the oxygen bond of In-O-In $[84,92-95,98,99]$.

The nature of the third peak $\mathrm{O}_{\text {III }}$ with maximum at $533.3 \mathrm{eV}$ [90] complies with chemisorbed oxygen and water related species, which is closely related to the hydroxyl groups, attached to the surfaces of samples and absorbed $\mathrm{O}_{2}$ from their ambient [91-95].

Behavior of the second peak $\mathrm{O}_{\mathrm{II}}$ at $532.0 \mathrm{eV}$ [96] was associated to oxygen that forms a rather stable phase in the terminal and subsurface areas of the NPs. These areas of the NPs exhibit deficiency of lattice oxygen, which corresponds to InO formula and such nonstoichiometric state of the surface may remain stable even after heat treatment in oxygen atmosphere [90]. It is important to note

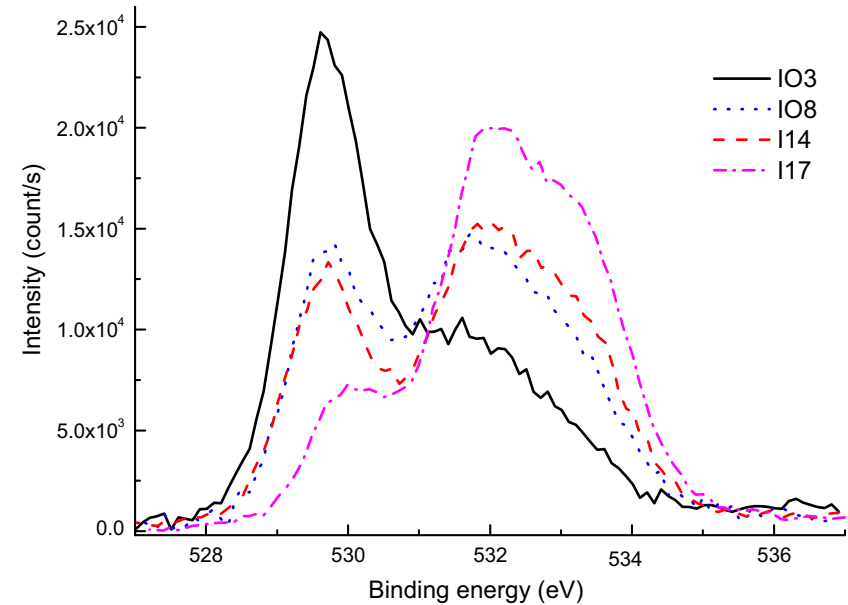

Fig. 14. High-resolution XPS spectra of some oxide-rich and metal-rich NPs in the core level region $01 \mathrm{~s}$.

that $\mathrm{O}_{\text {II }}$ peak, associated with an oxygen-deficient region, corresponds to the oxygen defects in the matrix of metal oxide $[92,93]$. As it is seen from Table S1 and Fig. 14, for the metal-rich NPs, the intensity of peak due to oxygen vacancies is rather high, indicating a large number of oxygen vacancies. Similar behavior has been observed earlier in the indium-oxide nanostructures $[94,98]$. Thus, it can be concluded that oxygen deficiencies exist in our NPs $[97,100]$.

Simulation of the 0 1s XPS spectra of our NPs reveal that the RTFM origin could be attributed to the singly charged oxygen vacancies, which are relatively easily created at interfaces and 


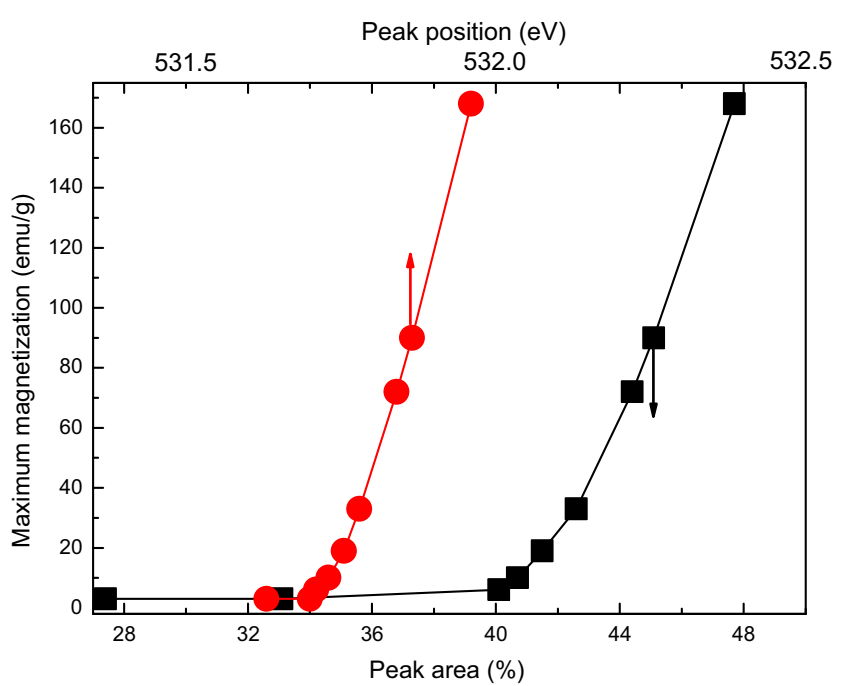

Fig. 15. Maximum magnetization of some NPs vs. $\mathrm{O}_{\text {II }}(\mathrm{O} 1 \mathrm{~s})$ peaks areas (in\%) and positions.

surfaces of the NPs [76]. Following Yang et al. [12], we may assume that these vacancies induce the RTFM, which may use the $\mathrm{F}^{+}$center exchange mechanism with one trapped electron to explain [101]. The electrons in these singly charged oxygen vacancies $\left(\mathrm{F}^{+}\right)$are strongly localized [102]. Once the $\mathrm{F}^{+}$center density reaches its critical value for magnetic percolation, these $\mathrm{F}^{+}$centers will overlap with each other and this will result in long-range ferromagnetic ordering [12]. In Fig. 15, the data for our NPs show that the progressive increase in the peaks areas and positions of $\mathrm{O} 1 \mathrm{~s} \mathrm{O}_{\mathrm{II}} \mathrm{com}-$ ponent is accompanied by an enhancement of the maximum magnetization. It is possible in the NPs, above a percolation threshold, strong mutual interactions of magnetic moments, associated with the defected states, really take place and the long-range ferromagnetic order may be established. The most likely, these interacting vacancies contribute to the net RTFM magnetization of our NPs $[19,103]$.

\section{Conclusions}

Oxide-rich and metal-rich $\mathrm{In} / \mathrm{In}_{2} \mathrm{O}_{3}$ aerosol-generated nanoparticles ranging in average particle sizes distributed from 30 up to $300 \mathrm{~nm}$ could be prepared by levitation-jet synthesis through condensation of indium metal vapor in an inert-gas flow under different synthetic parameters. SEM, BET, XRD, UV-vis, FT-IR, Raman, and XPS studies of uniform octahedral and rough-surface structured NPs demonstrate a predominant effect of microstructure on their properties. All the synthesized materials are ferromagnetic at room temperature with relatively high maximum magnetization of up to $0.17 \mathrm{emu} / \mathrm{g}$ and coercive force of up to 140 Oe. Maximum magnetization of $\mathrm{In} / \mathrm{In}_{2} \mathrm{O}_{3}$ NPs tends to grow with decrease in metal indium unit cell volume, followed an increasing in the Raman intensities and red shifts in the FT-IR peak positions. The XPS study discovers a pronounced dependence of maximum magnetization from the oxygen deficiency, suggesting that RTFM is due to oxygen vacancy confined to the surface of the NPs. Summary of all the experimental data obtained, may be interpreted in terms of the defect structure of the metal-oxide interface, containing In and $\mathrm{O}$ vacancies. These surface defects are key factors regulating the ferromagnetic ordering. Determination of the synthesis conditions of aerosol-generated NPs favoring reproducibility of their magnetic properties might be accepted as a starting point for the development of some devices using the spin polarization effect.

\section{Acknowledgment}

Authors are acknowledging partial financial support from the Russian Foundation for Basic Research (RFBR research project No. 13-03-12407).

\section{Appendix A. Supplementary material}

Supplementary data associated with this article can be found, in the online version, at http://dx.doi.org/10.1016/j.apt.2017.05.013.

\section{References}

[1] M. Venkatesan, C.B. Fitzgerald, J.M.D. Coey, Thin films: Unexpected magnetism in a dielectric oxide, Nature 430 (2004) 630.

[2] J.M.D. Coey, $d^{0}$ ferromagnetism, Solid State Sci. 7 (2005) 660-667.

[3] W. Prellier, A. Fouchet, B. Mercey, Oxide-diluted magnetic semiconductors: a review of the experimental status, J. Phys.: Condens. Matter 15 (2003) R1583.

[4] S. Mehraj, M.S. Ansari, A.A. Al-Ghamdi, Alimuddin, Annealing dependent oxygen vacancies in $\mathrm{SnO}_{2}$ nanoparticles: Structural, electrical and their ferromagnetic behavior, Mater. Chem. Phys. 171 (2016) 109-118.

[5] A. Sundaresan, R. Bhargavi, N. Rangarajan, U. Siddesh, C.N.R. Rao, Ferromagnetism as a universal feature of nanoparticles of the otherwise nonmagnetic oxides, Phys. Rev. B 74 (2006) 161306.

[6] S. Banerjee, M. Mandal, N. Gayathri, M. Sardar, Enhancement of ferromagnetism upon thermal annealing in pure $\mathrm{ZnO}$, Appl. Phys. Lett. 91 (2007) 182501.

[7] I.G. Morozov, O.V. Belousova, D. Ortega, M.-K. Mafina, M.V. Kuznetcov, Structural, optical XPS and magnetic properties of $\mathrm{Zn}$ particles capped by $\mathrm{ZnO}$ nanoparticles, J. Alloys and Compd. 633 (2015) 237-245.

[8] D. Gao, J. Zhang, J. Zhu, J. Qi, Z. Zhang, W. Sui, H. Shi, D. Xue, Vacancymediated magnetism in pure copper oxide nanoparticles, Nanoscale Res. Lett. 5 (2010) 769-772.

[9] M.V. Kuznetsov, M.-K. Mafina, O.V. Belousova, N.A. Vakin, S.Y. Shchipakin, I.G. Morozov, Catalytically active magnetic nanoparticles in the Cu-O system, Inorg. Mater. 51 (2015) 307-318.

[10] J. Hu, Z. Zhang, M. Zhao, H. Qin, M. Jiang, Room-temperature ferromagnetism in MgO nanocrystalline powders, Appl. Phys. Lett. 93 (2008) 192503.

[11] J. Li, Y. Jiang, Y. Li, D. Yang, Y. Xu, M. Yan, Origin of room temperature ferromagnetism in MgO films, Appl. Phys. Lett. 102 (2013) 072406.

[12] G. Yang, D. Gao, J. Zhang, J. Zhang, Z. Shi, D. Xue, Evidence of vacancy-induced room temperature ferromagnetism in amorphous and crystalline $\mathrm{Al}_{2} \mathrm{O}_{3}$ nanoparticles, J. Phys. Chem. C 115 (2011) 16814-16818.

[13] D. Gao, J. Li, Z. Li, Z. Zhang, J. Zhang, H. Shi, D. Xue, Defect-mediated magnetism in pure CaO nanopowders, J. Phys. Chem. C 114 (2010) 1170311707.

[14] S. Ghose, T. Rakshit, R. Ranganathan, D. Jana, Role of Zn-interstitial defect states on $d^{0}$ ferromagnetism of mechanically milled $\mathrm{ZnO}$ nanoparticles, RSC Adv. 5 (2015) 99766-99774.

[15] J. Osorio-Guillén, S. Lany, S.V. Barabash, A. Zunger, Nonstoichiometry as a source of magnetism in otherwise nonmagnetic oxides: magnetically interacting cation vacancies and their percolation, Physical Review B 75 (2007) 184421.

[16] L.-C. Tien, Y.-Y. Hsieh, Defect-induced ferromagnetism in undoped $\operatorname{In}_{2} \mathrm{O}_{3}$ nanowires, Mater. Res. Bull. 60 (2014) 690-694.

[17] C. Sudakar, A. Dixit, S. Kumar, M.B. Sahana, G. Lawes, R. Naik, V.M. Naik, Coexistence of anion and cation vacancy defects in vacuum-annealed $\mathrm{In}_{2} \mathrm{O}_{3}$ thin films, Scripta Mater. 62 (2010) 63-66.

[18] R. Prakash, S. Kumar, F. Ahmed, C.G. Lee, J.I. Song, Room temperature ferromagnetism in Ni doped $\mathrm{In}_{2} \mathrm{O}_{3}$ nanoparticles, Thin Solid Films 519 (2011) 8243-8246.

[19] S.K.S. Patel, K. Dewangan, S.K. Srivastav, N.S. Gajbhiye, Synthesis of monodisperse $\operatorname{In}_{2} \mathrm{O}_{3}$ nanoparticles and their $d^{0}$ ferromagnetism, Curr. Appl. Phys. 14 (2014) 905-908.

[20] N.H. Hong, J. Sakai, N. Poirot, V. Brizé, Room-temperature ferromagnetism observed in undoped semiconducting and insulating oxide thin films, Phys. Rev. B 73 (2006) 132404.

[21] R.P. Panguluri, P. Kharel, C. Sudakar, R. Naik, R. Suryanarayanan, V.M. Naik, A. G. Petukhov, B. Nadgorny, G. Lawes, Ferromagnetism and spin-polarized charge carriers in $\mathrm{In}_{2} \mathrm{O}_{3}$ thin films, Phys. Rev. B 79 (2009) 165208.

[22] S. Sun, P. Wu, P. Xing, $d^{0}$ ferromagnetism in undoped $n$ and p-type $\mathrm{In}_{2} \mathrm{O}_{3}$ films, Appl. Phys. Lett. 101 (2012) 132417.

[23] M. Naeem, S. Qaseem, I. Ahmad, M. Maqbool, Effect of size reduction on the electronic and ferromagnetic properties of the $\mathrm{In}_{2} \mathrm{O}_{3}$ nanoparticles, J. Nanopart. Res. 14 (2012) 1-8.

[24] S. Oaseem, S.R. Ali, M. Naeem, S. Rizvi, Size induced ferromagnetism in pristine indium oxide nanoparticles, Appl. Surf. Sci. 331 (2015) 87-91.

[25] J. Chandradass, D.S. Bae, K.H. Kim, A simple method to prepare indium oxide nanoparticles: structural, microstructural and magnetic properties, Adv. Powder Technol. 22 (2011) 370-374.

[26] N. Sai Krishna, S. Kaleemulla, G. Amarendra, N. Madhusudhana Rao, M. Kuppan, M. Rigana Begam, D. Sreekantha Reddy, Structural, optical and 
magnetic properties of $\left(\operatorname{In}_{1-x} \mathrm{Ni}_{\mathrm{x}}\right)_{2} \mathrm{O}_{3}(0 \leq \mathrm{x}<0.09)$ powders synthesized by solid state reaction, Mater. Sci. Semicond. Process. 18 (2014) 22-27.

[27] O.M. Lemine, M. Bououdina, A. Alyamani, K. Omri, K. Ibnaouf, M.A. Ibrahem, R. Alhathlool, Defect-induced room temperature ferromagnetism in mechanically milled nanocrystalline $\mathrm{In}_{2} \mathrm{O}_{3}$ powder, Mater. Lett. 181 (2016) $152-155$.

[28] I.G. Morozov, O.V. Belousova, O.A. Belyakov, I.P. Parkin, S. Sathasivam, M.V, Kuznetcov, Titanium nitride room-temperature ferromagnetic nanoparticles, J. Alloy. Compd. 675 (2016) 266-276.

[29] Y.G. Morozov, O.V. Belousova, M.V. Kuznetsov, D. Ortega, I.P. Parkin, Electric field-assisted levitation-jet aerosol synthesis of Ni/NiO nanoparticles, J. Mater. Chem. 22 (2012) 11214-11223.

[30] D. Ortega, M.V. Kuznetsov, Y.G. Morozov, O.V. Belousova, I.P. Parkin, Phase, size and shape controlled formation of aerosol generated nickel and nickel oxide nanoparticles, J. Alloy. Compd. 579 (2013) 495-501.

[31] K.K. Nanda, M. Rouenhoff, F.E. Kruis, Gas-phase synthesis of size-classified polyhedral $\mathrm{In}_{2} \mathrm{O}_{3}$ nanoparticles, J. Mater. Chem. 22 (2012) 3133-3138.

[32] M.H. Magnusson, B.J. Ohlsson, M.T. Björk, K.A. Dick, M.T. Borgström, K. Deppert, L. Samuelson, Semiconductor nanostructures enabled by aerosol technology, Front. Phys. 9 (2014) 398-418.

[33] M.V. Kuznetcov, O.V. Belousova, D. Ortega, I.G. Morozov, Ferromagnetic nanoparticles in Sn-O system, Inorg. Mater. 50 (2014) 793-802.

[34] T.A. Kondrat'eva, Y.G. Morozov, E.A. Chernov, Effect of conditions of manufacture on the properties of ultrafine nickel powder, Powder Metallurgy and Metal Ceram. 26 (1987) 793-795.

[35] Y.I. Petrov, Physics of small particles, Nauka Moscow 1982.

[36] A.N. Jigatch, I.O. Leipunskii, M.L. Kuskov, N.I. Stoenko, V.B. Storozhev, An apparatus for the production and study of metal nanoparticles, Instrum. Experim. Techn. 43 (2000) 839-845.

[37] A.P. Krasnov, Y.G. Morozov, E.A. Chernov, Characteristic features of the vaporization mechanism in the crucible-free production of aerosol particles, Powder Technol. 81 (1994) 93-98.

[38] M.A. Garcia, E.F. Pinel, J.D.L. Venta, A. Quesada, V. Bouzas, J.F. Fernández, J.J. Romero, M.S.M. González, J.L. Costa-Krämer, Sources of experimental errors in the observation of nanoscale magnetism, J. Appl. Phys. 105 (2009) 013925.

[39] Y. Hao, G. Meng, C. Ye, L. Zhang, Controlled synthesis of $\mathrm{In}_{2} \mathrm{O}_{3}$ octahedrons and nanowires, Cryst. Growth Des. 5 (2005) 1617-1621.

[40] E. Ye, S.Y. Zhang, S.H. Lim, S. Liu, M.Y. Han, Morphological tuning, selfassembly and optical properties of indium oxide nanocrystals, Phys. Chem. Chem. Phys. 12 (2010).

[41] S. Qin, W. Lei, D. Liu, P. Lamb, Y. Chen, Synthesis of single-crystal nanoparticles of indium oxide by "urea glass" method and their electrochemical properties, Mater. Lett. 91 (2013) 5-8.

[42] M. Kumar, V.N. Singh, F. Singh, K.V. Lakshmi, B.R. Mehta, J.P. Singh, On the origin of photoluminescence in indium oxide octahedron structures, Appl. Phys. Lett. 92 (2008) 171907.

[43] M. Kumar, V.N. Singh, B.R. Mehta, J.P. Singh, Tunable synthesis of indium oxide octahedra, nanowires and tubular nanoarrow structures under oxidizing and reducing ambients, Nanotechnology 20 (2009).

[44] J. Alberto Ramos Ramón, D. León Sánchez, M. Herrera Zaldívar, U. Pal, Morphology and defect evolution in vapor-grown $\mathrm{In}_{2} \mathrm{O}_{3}$ : $\mathrm{Sn}$ micro-/nanoparticles, Mater. Sci. Semicond. Process. 40 (2015) 943-953.

[45] N.H. Chou, X. Ke, P. Schiffer, R.E. Schaak, Room-temperature chemica synthesis of shape-controlled indium nanoparticles, J. Am. Chem. Soc. 130 (2008) 8140-8141.

[46] Z.L. Wang, Transmission electron microscopy of shape-controlled nanocrystals and their assemblies, J. Phys. Chem. B 104 (2000) 1153-1175.

[47] H. Lorenz, M. Stöger-Pollach, S. Schwarz, K. Pfaller, B. Klötzer, J. Bernardi, S. Penner, A new preparation pathway to well-defined $\mathrm{In}_{2} \mathrm{O}_{3}$ nanoparticles at low substrate temperatures, J. Phys. Chem. C 112 (2008) 918-925.

[48] L. Gao, Z. Cheng, Q. Xiang, Y. Zhang, J. Xu, Porous corundum-type In2O3 nanosheets: Synthesis and NO2 sensing properties, Sensors and Actuators B: Chemical 208 (2015) 436-443.

[49] S. Elouali, L.G. Bloor, R. Binions, I.P. Parkin, C.J. Carmalt, J.A. Darr, Gas sensing with nano-indium oxides $\left(\mathrm{In}_{2} \mathrm{O}_{3}\right)$ prepared via continuous hydrothermal flow synthesis, Langmuir 28 (2012) 1879-1885.

[50] F. Gu, L. Zhang, Z. Wang, D. Han, G. Guo, Fine-tuning the structure of cubic indium oxide and their ethanol-sensing properties, Sens. Actuat. B: Chem. 193 (2014) 669-678.

[51] S. Sonsupap, E. Swatsitang, S. Maensiri, K. Wongsaprom, Synthesis and characterization of indium oxide nanoparticles using indium nitrate and polyvinylpyrrolidone (PVP) as precursors, Chiang Mai J. Sci. 42 (2015) 752760.

53] Y.G. Morozov, D. Ortega, O.V. Belousova, L.P. Parkin, M.V. Kuznetsov, Some peculiarities in the magnetic behavior of aerosol generated $\mathrm{NiO}$ nanoparticles, J. Alloy. Compd. 572 (2013) 150-157.

[54] M. Wang, Y. Tian, J.-M. Zhang, C.-F. Guo, X.-Z. Zhang, Q. Liu, Raman scattering in $\mathrm{In} / \mathrm{InO}_{\mathrm{x}}$ core-shell structured nanoparticles, Chin. Phys. B 23 (2014) 087803.

[55] Magnetic susceptibility of the elements and inorganic compounds, in: CRC Handbook of Chemistry and Physics, 96tht Editon, Press, CRC, 2015, pp. 4133.

[56] S. Batakrushna, G.P. K., D. Soumen, I. Kenji, F. Minoru, Oxygen vacancymediated enhanced ferromagnetism in undoped and Fe-doped $\mathrm{TiO}_{2}$ nanoribbons, J. Phys. D Appl. Phys. 47 (2014) 235304.
[57] M.V. Kuznetsov, Y.G. Morozov, O.V. Belousova, D. Ortega, Ferromagnetic Zn/ ZnO nanoparticles, Inorg. Mater. 50 (2014) 369-378.

[58] P. Esquinazi, W. Hergert, D. Spemann, A. Setzer, A. Ernst, Defect-induced magnetism in solids, IEEE Trans. Magn. 49 (2013) 4668-4674.

[59] M.A. Ramos, J. Barzola-Quiquia, P. Esquinazi, A. Muñoz-Martin, A. ClimentFont, M. García-Hernández, Magnetic properties of graphite irradiated with MeV ions, Physical Review B 81 (2010) 214404.

[60] A. Ayeshamariam, M. Bououdina, C. Sanjeeviraja, Optical, electrical and sensing properties of $\mathrm{In}_{2} \mathrm{O}_{3}$ nanoparticles, Mater. Sci. Semicond. Process. 16 (2013) 686-695.

[61] S.K. Chong, S.N.A. Azizan, K.W. Chan, H.-Q. Nguyen, W.S. Chiu, Z. Aspanut, C.F. Dee, S.A. Rahman, Structure deformation of indium oxide from nanoparticles into nanostructured polycrystalline films by in situ thermal radiation treatment, Nanoscale Res. Lett. 8 (2013) 1-9.

[62] S. Lacombe, H. Cardy, N. Soggiu, S. Blanc, J.L. Habib-Jiwan, J.P. Soumillion, Diffuse reflectance UV-Visible spectroscopy for the qualitative and quantitative study of chromophores adsorbed or grafted on silica, Microporous Mesoporous Mater. 46 (2001) 311-325.

[63] J. Tauc, Amorphous and liquid semiconductors, Springer Science \& Business Media, 2012.

[64] R.L. Weiher, R.P. Ley, Optical properties of indium oxide, J. Appl. Phys. 37 (1966) 299-302.

[65] P.D.C. King, T.D. Veal, F. Fuchs, C.Y. Wang, D.J. Payne, A. Bourlange, H. Zhang, G.R. Bell, V. Cimilla, O. Ambacher, R.G. Egdell, F. Bechstedt, C.F. McConville, Band gap, electronic structure, and surface electron accumulation of cubic and rhombohedral $\mathrm{In}_{2} \mathrm{O}_{3}$, Phys. Rev. B 79 (2009).

[66] H. Zhou, W. Cai, L. Zhang, Photoluminescence of indium-oxide nanoparticles dispersed within pores of mesoporous silica, Appl. Phys. Lett. 75 (1999).

[67] A. Murali, A. Barve, V.J. Leppert, S.H. Risbud, Synthesis and characterization of indium oxide nanoparticles, Nano Letters 1 (2001).

[68] L. Gai, L. Ma, H. Jiang, Y. Ma, Y. Tian, H. Liu, Nitrogen-doped $\operatorname{In}_{2} \mathrm{O}_{3}$ nanocrystals constituting hierarchical structures with enhanced gas-sensing properties, Cryst.Eng.Comm. 14 (2012) 7479-7486.

[69] E.C.C. Souza, J.F.Q. Rey, E.N.S. Muccillo, Synthesis and characterization of spherical and narrow size distribution indium oxide nanoparticles, Appl. Surf. Sci. 255 (2009) 3779-3783.

[70] J.F.Q. Rey, T.S. Plivelic, R.A. Rocha, S.K. Tadokoro, I. Torriani, E.N.S. Muccillo, Synthesis of $\mathrm{In}_{2} \mathrm{O}_{3}$ nanoparticles by thermal decomposition of a citrate gel precursor, J. Nanopart. Res. 7 (2005) 203-208.

[71] W.B. White, V.G. Keramidas, Vibrational spectra of oxides with the C-type rare earth oxide structure, Spectrochim. Acta, Part A 28 (1972) 501-509.

[72] C.Y. Wang, Y. Dai, J. Pezoldt, B. Lu, T. Kups, V. Cimalla, O. Ambacher, Phase stabilization and phonon properties of single crystalline rhombohedral indium oxide, Cryst. Growth Des. 8 (2008) 1257-1260.

[73] C. Kranert, R. Schmidt-Grund, M. Grundmann, Raman active phonon modes of cubic $\mathrm{In}_{2} \mathrm{O}_{3}$, Phys. Status Solidi (RRL) Rapid Res. Lett. 8 (2014) 554-559.

[74] http://www.casaxps.com/ (2016).

[75] J.B. Yi, N.N. Bao, X. Luo, H.M. Fan, T. Liu, S. Li, Ferromagnetism in Cr doped $\mathrm{In}_{2} \mathrm{O}_{3}$, Thin Solid Films 531 (2013) 481-486

[76] W.A. Adeagbo, G. Fischer, A. Ernst, W. Hergert, Magnetic effects of defect pair formation in ZnO, J. Phys.: Condens. Matter 22 (2010) 436002.

[77] https://kartyush.wordpress.com/, (2016).

[78] R. Holm, S. Storp, ESCA studies of chemical shifts for metal oxides, Applied physics 9 (1976) 217-222.

[79] J.R. Bosnell, R. Waghorne, On the structure of indium oxide-tin oxide transparent conducting films by electron diffraction and electron spectroscopy, Thin Solid Films 15 (1973) 141-148.

[80] Z. Jiang, D. Jiang, Z. Yan, D. Liu, K. Qian, J. Xie, A new visible light active multifunctional ternary composite based on $\mathrm{TiO}_{2}-\mathrm{In}_{2} \mathrm{O}_{3}$ nanocrystals heterojunction decorated porous graphitic carbon nitride for photocatalytic treatment of hazardous pollutant and $\mathrm{H}_{2}$ evolution, Appl. Catal. B 170-171 (2015) 195-205.

[81] Z. Jin, W. Duan, W. Duan, B. Liu, X. Chen, F. Yang, J. Guo, Indium doped and carbon modified P25 nanocomposites with high visible-light sensitivity for the photocatalytic degradation of organic dyes, Appl. Catal. A 517 (2016) $129-140$.

[82] J.C.C. Fan, J.B. Goodenough, X-ray photoemission spectroscopy studies of Sndoped indium-oxide films, J. Appl. Phys. 48 (1977) 3524-3531.

[83] B. Li, Y. Xie, M. Jing, G. Rong, Y. Tang, G. Zhang, $\mathrm{In}_{2} \mathrm{O}_{3}$ hollow microspheres: synthesis from designed $\operatorname{In}(\mathrm{OH})_{3}$ precursors and applications in gas sensors and photocatalysis, Langmuir 22 (2006) 9380-9385.

[84] J. Gan, X. Lu, J. Wu, S. Xie, T. Zhai, M. Yu, Z. Zhang, Y. Mao, S.C.I. Wang, Y. Shen, Y. Tong, Oxygen vacancies promoting photoelectrochemical performance of $\mathrm{In}_{2} \mathrm{O}_{3}$ nanocubes, Scientific Reports 3 (2013) 1021.

[85] Y. Masuda, M. Kondo, K. Koumoto, Site-selective deposition of $\mathrm{In}_{2} \mathrm{O}_{3}$ using a self-assembled monolayer, Cryst. Growth Des. 9 (2009) 555-561.

[86] R.K. Singhal, A. Samariya, S. Kumar, S.C. Sharma, Y.T. Xing, U.P. Deshpande, T. Shripathi, E. Saitovitch, A close correlation between induced ferromagnetism and oxygen deficiency in Fe doped $\mathrm{In}_{2} \mathrm{O}_{3}$, Appl. Surf. Sci. 257 (2010) $1053-$ 1057.

[87] Z. Li, X. Tao, Y. Cheng, Z. Wu, Z. Zhang, H. Dang, A simple and rapid method for preparing indium nanoparticles from bulk indium via ultrasound irradiation, Mater. Sci. Eng., A 407 (2005) 7-10.

[88] Y.I. Choi, S.K. Kim, S.W. Lee, Y. Sohn, Metallic indium spheres by the anaerobic ethanol oxidation of indium oxide, J. Alloy. Compd. 687 (2016) 611-615.

[89] http://xpssimplified.com/elements/indium.php, (2016). 
[90] V. Golovanov, M.A. Mäki-Jaskari, T.T. Rantala, G. Korotcenkov, V. Brinzari, A Cornet, J. Morante, Experimental and theoretical studies of indium oxide gas sensors fabricated by spray pyrolysis, Sens. Actuat. B: Chem. 106 (2005) 563571.

[91] J.Q. Xu, Y.P. Chen, Q.Y. Pan, Q. Xiang, Z.X. Cheng, X.W. Dong, A new route fo preparing corundum-type $\mathrm{In}_{2} \mathrm{O}_{3}$ nanorods used as gas-sensing materials, Nanotechnology 18 (2007) 115615.

[92] M. Kim, J. Kim, J. Cho, H. Kim, N. Lee, B. Choi, A study of the characteristics of indium tin oxide after chlorine electro-chemical treatment, Mater. Res. Bull. 82 (2016) 115-121.

[93] J. Li, F. Li, X. Zhu, D. Lin, Q. Li, W. Liu, Z. Xu, Colossal dielectric permittivity in hydrogen-reduced rutile $\mathrm{TiO}_{2}$ crystals, J. Alloy. Compd. 692 (2017) 375-380.

[94] Y. Xing, W. Que, X. Yin, Z. He, X. Liu, Y. Yang, J. Shao, L.B. Kong, $\mathrm{In}_{2} \mathrm{O}_{3} / \mathrm{Bi}_{2} \mathrm{Sn}_{2} \mathrm{O}_{7}$ heterostructured nanoparticles with enhanced photocatalytic activity, Appl. Surf. Sci. 387 (2016) 36-44.

[95] J. Xu, Y. Wan, Y. Huang, Y. Wang, L. Qin, H.J. Seo, Synthesis, surface properties and photocatalytic abilities of semiconductor $\mathrm{In}_{2} \mathrm{Cu}_{2} \mathrm{O}_{5}$ nanoparticles, Appl. Surf. Sci. 389 (2016) 639-644.

[96] A.W.C. Lin, N.R. Armstrong T. Kuwana, X-ray photoelectron/Auger electron spectroscopic studies of tin and indium metal foils and oxides, Anal. Chem. 49 (1977) 1228-1235.

[97] X.S. Peng, G.W. Meng, X.F. Wang, Y.W. Wang, J. Zhang, X. Liu, L.D. Zhang Synthesis of Oxygen-Deficient Indium-Tin-Oxide (ITO) Nanofibers, Chem. Mater. 14 (2002) 4490-4493.
[98] D.V. Shinde, D.Y. Ahn, V.V. Jadhav, D.Y. Lee, N.K. Shrestha, J.K. Lee, H.Y. Lee, R. S. Mane, S.-H. Han, A coordination chemistry approach for shape controlled synthesis of indium oxide nanostructures and their photoelectrochemical properties, J. Mater. Chem. A 2 (2014) 5490-5498.

[99] L. Yang S, Guo, O Yang Y. Zhu, B. Dai, H. Yu, P. Lei, J. Han, Y. Hou, J. Zhu, Improved work function of preferentially oriented indium oxide films induced by the plasma exposure technique, Electron. Mater. Lett. 11 (2015) 938-943.

[100] P. Reunchan, X. Zhou, S. Limpijumnong, A. Janotti, C.G. Van de Walle, Vacancy defects in indium oxide: an ab-initio study, Curr. Appl. Phys. 11 (2011) S296S300.

[101] R.K. Singhal, S. Kumar, P. Kumari, Y.T. Xing, E. Saitovitch, Evidence of defectinduced ferromagnetism and its "switch" action in pristine bulk $\mathrm{TiO}_{2}$, Appl. Phys. Lett. 98 (2011) 092510.

[102] R.S. Lubna, A. Bakhtyar, Z. Hao, W.G. Wang, Y.Q. Song, H.W. Zhang, S.I. Shah, J. Q. Xiao, Detailed study on the role of oxygen vacancies in structural, magnetic and transport behavior of magnetic insulator: $\mathrm{Co}-\mathrm{CeO}_{2}$, J. Phys.: Condens. Matter 21 (2009) 486004.

[103] M. Bououdina, A.A. Dakhel, M. El-Hilo, D.H. Anjum, M.B. Kanoun, S. GoumriSaid, Revealing a room temperature ferromagnetism in cadmium oxide nanoparticles: an experimental and first-principles study, RSC Adv. 5 (2015) 33233-33238. 